\title{
Linking Credit Risk Premia to the Equity Premium
}

\author{
Tobias Berg* \\ Technische Universität München \\ Arcisstr. 21 \\ D-80290 Munich \\ Germany \\ +49 8928925489 (Phone) \\ +49 8928925488 (Fax) \\ tobias.berg@wi.tum.de \\ Christoph Kaserer ${ }^{\dagger}$ \\ Technische Universität München \\ Arcisstr. 21 \\ D-80290 Munich \\ Germany \\ +49 8928925490 (Phone) \\ +49 8928925488 (Fax) \\ christoph.kaserer@wi.tum.de
}

This version: September 2008

\begin{abstract}
We estimate the equity premium using CDS spreads and structural models of default. Our estimates yield equity premia of $6.50 \%$ (U.S.), $5.44 \%$ (Europe) and $6.21 \%$ (Asia) based on 5year CDS spreads from 2003-2007. Due to some conservative assumptions these estimates are upper limits for the equity premium. Using 3-, 7- and 10-year CDS maturities yields similar results and offers an opportunity to estimate the term structure of risk premia. Although our estimator is developed in a Merton framework it is robust with respect to model changes (first-passage, strategic default, Duffie/Lando (2001) framework).
\end{abstract}

Keywords: equity premium, credit risk premium, credit risk, structural models of default JEL classification codes: G13, G31

\footnotetext{
${ }^{*}$ Corresponding author: Tobias Berg, Department of Financial Management and Capital Markets, Technische Universität München

${ }^{\dagger}$ Prof. Christoph Kaserer, Department of Financial Management and Capital Markets, Technische Universität München
} 


\section{Introduction}

Risk premia in equity markets are a widely researched topic. The risk premium in equity markets is usually defined as the equity premium, e.g. the excess return of equities over risk free bonds. The literature discusses three different ways for the measurement of the equity premium: Models based on historical realizations, discounted cash-flow models and models based on utility functions. While historical averages have long dominated theory and practical applications, current research suggests an upward bias for the U.S. market, e.g. the ex post realized equity returns do not correctly mirror the ex ante priced equity premium. Among other things, this can be explained by survivorship bias, risk premium volatility, enhanced diversification possibilities, interest rate level and state of the economy; cf. for example Illmanen (2003) and Fama/French (2002). In the U.S., historical averages have been around 7-9\% depending on the time horizon and methodology (arithmetic/geometric) used (cf. Fama/French (2002) and Ibbotson (2006)). Discounted cash-flow models have become more popular recently, but are also subject to debate, in particular for their high sensitivity to forecasts of dividend- or earnings growth rates. Estimations based on such models yield implied equity premia in the range from 1\%-9\%, cf. Claus/Thomas (2001), Gebhardt/Lee/Swaminathan (2001), Fama/French (2002), Gode/Mohanram (2003), Easton et.al. (2002) and Easton (2004). Approaches based on utility functions have been subject to intensive debate in the academic literature - mainly based on the 'Equity Premium Puzzle' put forward by Mehra/Prescott (1985) - its use in practical applications is, however, currently of minor importance.

The risk aversion of investors influences both credit prices and returns as well. As an example, we have looked at credit default swap (CDS) contracts of A-rated obligors in the CDS-index CDX.NA.IG from 2003-2007. The average 5-year CDS spread has been $37 \mathrm{bp}$, whereas the average annual expected loss (EL) is only appr. 9 bp. Therefore, these 5-year CDS investments yield an average return of appr. $28 \mathrm{bp}(=37 \mathrm{bp}-9 \mathrm{bp})$ above the risk free rate, as can be seen from table I. In absolute terms, this premium increases with decreasing credit quality, i.e. the expected net returns increases with increasing riskyness. Measured relative to the expected loss (or the actual default probability) it decreases with declining credit quality. Over the last years, research on this default risk premium has developed, but there has not yet emerged consensus on the methodology for measuring these default premia. Current approaches mainly use simple ratios or differences between risk neutral and actual default probabilities, cf. for example Berndt et.al. (2005) and Hull et.al. (2005).

We use structural models of default to convert credit spreads into an equity premium. Specifying a specific structural model, one can derive the risk neutral and the actual default probability. Used the other way around, the difference between risk neutral and actual default probability yields the dynamics of the asset value process, in particular the asset Sharpe ratio. Together with the 


\begin{tabular}{ccccc}
\hline Rating grade & Average 5-y-CDS-mid (bp) & Average 5-y-EL p.a. (bp) & $\Delta(\mathrm{bp})$ & Q-to-P \\
\hline AA & 31.53 & 5.23 & 26.30 & 6.03 \\
A & 37.37 & 9.17 & 28.20 & 4.07 \\
Baa1 & 48.43 & 14.60 & 33.83 & 3.32 \\
Baa2 & 56.91 & 22.00 & 34.91 & 2.59 \\
Baa3 & 68.51 & 33.17 & 35.34 & 2.07 \\
\hline
\end{tabular}

Table I:

Credit risk premia

Credit risk premia for 5-year CDS (Index CDX.NA.IG, 2003-2007) based on Moody's rating and a recovery rate of $45 \% . \Delta(b p)$ : difference in bp between 5-year-CDS spread and 5-year-EL p.a. Q-to-P: ratio of CDS spread to EL p.a.

asset correlation and the implied volatility, we are then able to derive the market Sharpe ratio and the equity premium. Our approach is probably most similar to Bohn (2000), Agrawal/Arora/Bohn (2004) and Huang/Huang (2005). Our contribution is threefold: First, we use a closed form solution for the estimation of the market Sharpe ratio and the equity premium derived in a Merton framework. To our best knowledge we are the first ones to extend this estimator to first-passage-models, strategic default models and models with incomplete information based on Duffie/Lando (2001). Second, we apply the estimator to more than 150,000 CDS spreads from the major CDS indices in the U.S., Europe and Asia. Using CDS helps to mitigate the 'risk-free-rate-problem' (c.f. Hull et.al. (2004)), i.e. we do not have to estimate/choose the correct corresponding risk-free rate. By using constituents of a liquid CDS index we avoid the 'size-problem'1 and should be less exposed to liquidity risk issues. Third, we perform a rich set of robustness tests including different specifications for the real world default probability based on hazard rate models.

The estimator of the market Sharpe ratio and the equity premium derived in this paper has three important characteristics which make it very convenient. First, it is only based on observable parameters, i.e. risk neutral and actual default probabilities, the maturity and the equity correlation. The risk neutral default probability and the maturity can be derived from CDS spreads, the actual default probability from ratings ${ }^{2}$ and the correlation from equity prices. Unlike other applications of structural models, we do neither have to calibrate the asset value process nor the default barrier. Second, the estimator is robust with respect to model changes. We examine a classical first passage time model and the Duffie/Lando (2001) model which incorporates strategic default and unobservable asset values. Third, the estimator is robust with respect to noise in the input parameters. As an illustration, we look at a model-based 5-year spread of a

\footnotetext{
${ }^{1}$ Various literature has pointed out to the fact that size plays a role in (expected) returns and Sharpe ratios, c.f. e.g. Fama/French $(1993,1996)$. There are also indications that the size effect plays an important role in credit markets as well, c.f. Agrawal/Arora/Bohn (2004).

${ }^{2}$ We use EDFs (expected default frequencies) from Moody's KMV and - as a robustness test - agencies (Moody's/S\&P/fitch) ratings and a multi-period hazard rate model.
} 
BBB-rated obligor. This credit spread is $37 \mathrm{bp}$ for a company Sharpe ratio of $10 \%$, it is $140 \mathrm{bp}$ for a company Sharpe ratio of $40 \%$ (cf. subsection II.A for a detailled analysis). This large difference indicates that common noise in the data ${ }^{3}$ will not significantly reduce the possibility to extract the Sharpe ratio and the equity premium out of credit spreads. Mathematically, the sensitivity of the model-based credit spread with respect to the Sharpe ratio is 'high' compared to other noise in the data.

We have applied our equity premium estimator to the constituents of the main CDS indices in the U.S. (from 2003-2007) and for Europe and Asia (from 2004 to 2007). The risk neutral default probability was derived from CDS spreads, EDFs (expected default frequencies) from KMV were used as the primary source for the actual default probability. We estimate equity premia of $6.50 \%$ for the U.S., $5.44 \%$ for Europe and $6.21 \%$ for Asia. Due to some conservative assumptions ${ }^{4}$ these estimates are upper limits for the equity premium. This confirms former research that the historical equity premium is upward biased. The results are quite stable over time, e.g. for the U.S. equity premia estimates range from $5.16 \%$ in 2004 to $7.18 \%$ in 2005. Using different CDS maturities (3-, 7- and 10-year) to estimate the equity premium also results in similar - though slightly smaller estimates for the equity premium. Our approach could also be used as a starting point to estimate the term structure of risk premia.

The remainder of the paper is structured as follows. Section II describes the theoretical framework for credit risk premia based on asset value models. We examine a classical Merton model, a first passage time model and a model based on unobservable asset values as proposed by Duffie/Lando (2001). Section III describes our data and provides descriptive statistics. The equity premium estimates for the U.S based on 5-year CDS are reported in section IV, results from other maturities (3-, 7- and 10-year) and other markets (Europe and Asia) are reported in section V. To confirm the robustness of our results, we conducted extensive sensitivity analysis which we report in section VI. Section VII concludes.

\section{Model setup}

The basic idea is to measure the excess return on debt and postulate a model linking debt valuation to asset valuation and asset valuation to equity valuation. Excess returns on debt instruments can then be transformed into excess returns on equity instruments. Technically, we use structural models of default to derive a relationship between risk neutral and actual default probabilities. Empirically, most structural models perform poorly, cf. Eom et.al. (2000). One of the main reasons is the calibration process usually needed to specifiy structural models, e.g.

\footnotetext{
${ }^{3}$ E.g. bid-ask spreads, liquidity effects and inaccuracies in determining the actual default probability.

${ }^{4}$ In particular we assume that $100 \%$ of the CDS spread is attributable to credit risk.
} 
determination of leverage, asset volatilities etc. In contrast to mainstream literature, we do however not aim to derive actual and risk neutral default probabilities from structural models. We are simply interested in the relation between risk neutral and actual default probabilities. Hence, we simply assume that there exists a structural model that yields the correct actual default probability and from there derive the risk neutral default probability. It is therefore not necessary to perform the calibration process that is usually required. Our approach is probably most similar to Huang/Huang (2005) and Bohn (2000). Our approach differs though in at last three ways: First, we explicitly focus on models with information uncertainty; second, we use CDS spreads, which should be less sensitive to liquidity distortions; third, we are to our best knowledge - the first who directly aim to extract the equity premium out of credit prices.

Subsection A starts with the classical Merton model. We derive a simple Merton estimator for the market Sharpe ratio and the equity premium. This estimator is only based on observable parameters, i.e. the risk neutral and actual default probability, the maturity and equity correlations. Subsection B and appendix A expand this framework to first passage time models, strategic default models and models with unobservable asset values based on Duffie/Lando (2001).

\section{A Equity premium estimation in the Merton framework}

Structural models for the valuation of debt and the determination of default probabilities are already mentioned in Black/Scholes (1973). The Merton framework presented in this subsection is based on Merton (1974), who explicitely focusses on the pricing of corporate debt. In this framework a company's debt consists of one zero-bond. Default occurs if the asset value of the company falls below the nominal value $N$ of the zero bond at maturity of the bond. A company can therefore only default at one point in time, which obviously poses a simplification of the real world. The asset value $V_{t}$ is modelled as a geometric Brownian motion with volatility $\sigma$ and drift $\mu=\mu_{V}$ (actual drift) and $r$ (risk neutral drift) respectively, i.e. $d V_{t}^{P}=\mu V_{t} d t+\sigma V_{t} d B_{t}$ and $d V_{t}^{Q}=r V_{t} d t+\sigma V_{t} d B_{t}$, where $B_{t}$ denotes a standard Wiener process. In this framework, the real world default probability $P^{d e f}(t, T)$ between $t$ and $T$ can be calculated as follows:

$$
\begin{aligned}
P^{\text {def }}(t, T)=P\left[V_{T}<N\right] & =P\left[V_{t} \cdot e^{\left(\mu-\frac{1}{2} \sigma^{2}\right) \cdot(T-t)+\sigma \cdot\left(B_{T}-B_{t}\right)}<N\right] \\
& =P\left[\sigma \cdot\left(B_{T}-B_{t}\right)<\ln \left(\frac{N}{V_{t}}\right)-\left(\mu-\frac{1}{2} \sigma^{2}\right) \cdot(T-t)\right] \\
& =\Phi\left[\frac{\ln \frac{N}{V_{t}}-\left(\mu-\frac{1}{2} \sigma^{2}\right) \cdot(T-t)}{\sigma \cdot \sqrt{T-t}}\right] .
\end{aligned}
$$


The default probability under the risk neutral measure Q can be determined accordingly as

$$
Q^{d e f}(t, T)=Q\left[V_{T}<N\right]=\Phi\left[\frac{\ln \frac{N}{V_{t}}-\left(r-\frac{1}{2} \sigma^{2}\right) \cdot(T-t)}{\sigma \cdot \sqrt{T-t}}\right] .
$$

Combining (1) and (2) yields (cf. Duffie/Singleton (2003))

$$
Q^{d e f}(t, T)=\Phi\left[\Phi^{-1}\left(P^{d e f}(t, T)\right)+\frac{\mu-r}{\sigma} \cdot \sqrt{T-t}\right]
$$

which can be transformed to estimate the Sharpe ratio of the companies assets $\left(S R_{V}\right)$ :

$$
S R_{V}:=\frac{\mu-r}{\sigma}=\frac{\Phi^{-1}\left(Q^{\operatorname{def}}(t, T)\right)-\Phi^{-1}\left(P^{\operatorname{def}}(t, T)\right)}{\sqrt{T-t}}
$$

Please note, that the formula is still correct if we introduce a non-stochastic, constant payout ratio $\delta$. Relationship (4) is a central formula in our paper. It has two main advantages that make it convenient for our purpose: First, it directly yields the Sharpe ratio of the assets, i.e. neither $\mu_{V}$ and $\sigma_{V}$ nor $V_{t}, \mathrm{~N}$ or $\mathrm{r}$ have to be estimated separately. In contrast to other applications of structural models we do not have to calibrate any parameter of the asset value process. The company Sharpe ratio can simply be estimated based on actual and risk neutral default probabilities and the maturity. Second, it is robust with respect to model changes. This will be discussed in the next subsection and in the appendix. A graphical illustration of the relationship between risk neutral and actual default probabilities, Sharpe ratio and maturity is given in figure 1.

If we try to extract the market Sharpe ratio out of (4), we are faced with an additional problem: The Sharpe ratio of the assets $\frac{\mu_{V}-r}{\sigma_{V}}$ will usually differ from the market Sharpe ratio, since the assets $V_{t}$ will not necessarily be on the efficient frontier. The Sharpe ratio of the assets does not only capture the risk preference of investors, but also depends on the correlation of the assets with the market portfolio. The market Sharpe ratio can be calculated via a straight forward application of the CAPM: ${ }^{5}$

$$
\mu_{V}=r+\frac{\mu_{M}-r}{\sigma_{M}} \cdot \rho_{V, M} \cdot \sigma_{V} \Leftrightarrow \frac{\mu_{M}-r}{\sigma_{M}}=\frac{\mu_{V}-r}{\sigma_{V}} \cdot \frac{1}{\rho_{V, M}},
$$

where $\rho_{V, M}$ denotes the correlation coefficient between the asset returns and the market returns.

\footnotetext{
${ }^{5}$ We assume $\rho_{V, M} \neq 0$.
} 


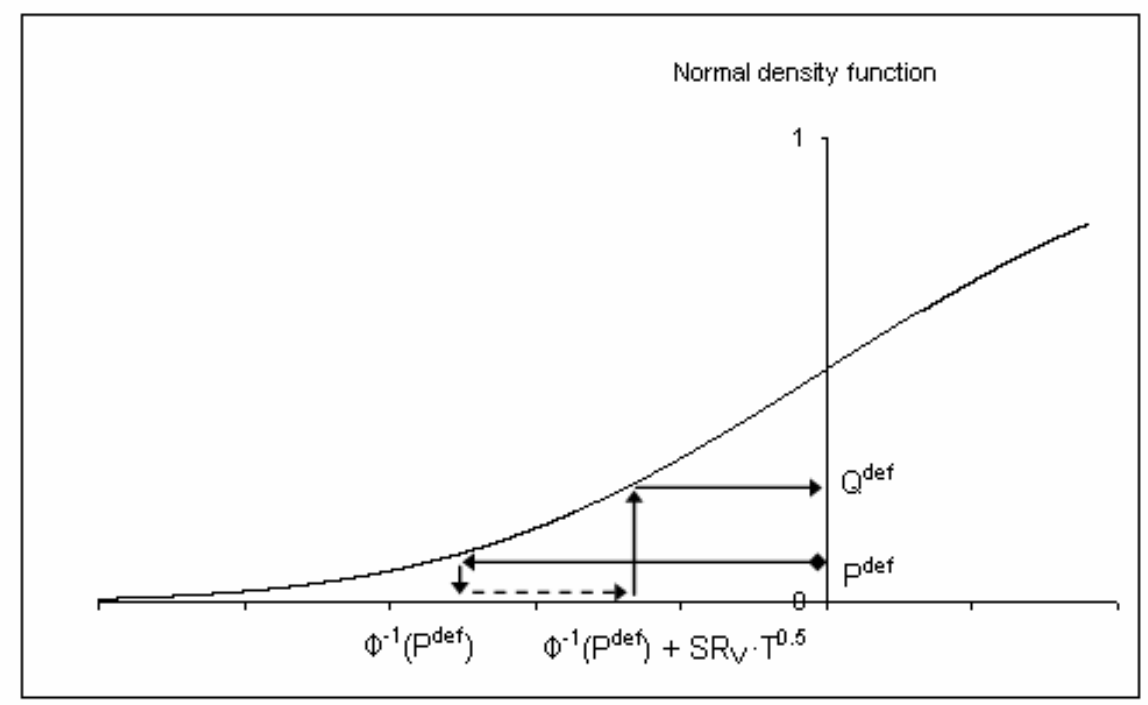

Figure 1: Illustration of the relationship between actual and risk neutral default probabilities in the Merton framework. $P D^{\text {def }}$ : actual cumulative default probability, $Q^{\text {def }}$ : risk neutral cumulative default probability, $S R_{V}$ : Sharpe ratio of the assets, T: maturity.

Therefore we will need an estimate of the correlation between the asset value and the market portfolio. This correlation $\rho_{V, M}$ can be approximated by the correlation between the corresponding equity return and the market return (denotet by $\rho_{E, M}$ ), i.e. by

$$
\rho_{V, M} \approx \rho_{E, M} .
$$

The error of this approximation is negligible, since - within the Merton framework - the equity value of a company equals a deep-in-the-money call option on the assets. The option is deep-in-themoney, since annual default probabilities are less than $0.4 \%$ for investment grade companies and less than $10 \%$ for all obligors rated B and above. For deep-in-the-money options, gamma is appr. zero, i.e. we have an almost affine linear relationship between asset and equity value, cf. Hull (2005) for example. For reasonable parameter choices, the approximation error is less than $3 \%$ (for rating grades above B) and 1\% (for investment grade ratings) respectively (cf. Appendix B for details). Hence, the following approximation holds:

$$
\frac{\mu_{M}-r}{\sigma_{M}} \approx \frac{\Phi^{-1}\left(Q^{\text {def }}(t, T)\right)-\Phi^{-1}\left(P^{\operatorname{def}}(t, T)\right)}{\sqrt{T-t}} \cdot \frac{1}{\rho_{E, M}} .
$$

Therefore, we define the Merton estimator of the market Sharpe ratio as:

$$
\widehat{\gamma}_{\mathrm{SR}_{\mathrm{M}}, \text { Merton }}:=\frac{\Phi^{-1}\left(Q^{\text {def }}(t, T)\right)-\Phi^{-1}\left(P^{\text {def }}(t, T)\right)}{\sqrt{T-t}} \frac{1}{\rho_{E, M}}
$$


Including the (expected) volatility of the market portfolio $\sigma_{M}$ yields an estimator for the equity premium:

$$
\widehat{\gamma}_{\mathrm{EP}, \text { Merton }}:=\frac{\Phi^{-1}\left(Q^{\operatorname{def}}(t, T)\right)-\Phi^{-1}\left(P^{\text {def }}(t, T)\right)}{\sqrt{T-t}} \frac{\sigma_{M}}{\rho_{E, M}}
$$

Please note, that we will need a sufficient sensitivity of the risk neutral default probability $Q^{\text {def }}(t, T)$ with respect to the Sharpe ratio for an empirical application. Otherwise noise in the data (e.g. bid-ask-spreads, inaccuracies in determining correlations and actual default probailities) will result in a very inaccurate estimation. That this sensitivity is large enough can be seen from the first derivative of (3) with respect to the Sharpe ratio:

$$
\frac{\partial Q^{\operatorname{def}}(T)}{\partial S R_{V}}=\frac{1}{\sqrt{2 \pi}} \cdot e^{-\frac{1}{2}\left(S R_{V} \cdot T+\Phi^{-1}\left(P^{\operatorname{def}}(T)\right)\right)^{2}} \cdot T .
$$

If we look, for example, at a BBB-rated obligor with a 5-year cumulative actual default probability of appr. $2.17 \%$, the resulting model-based risk neutral default probability should be either $3.6 \%$ (for an asset Sharpe ratio of $10 \%$ ) or $13 \%$ (for an asset Sharpe ratio of $40 \%$ ) respectively (based on (3)). Assuming a recovery rate (RR) of $50 \%$ transforms this into a CDS spread of either $37 \mathrm{bp}$ or 140 bp. ${ }^{6}$ This large difference indicates that noise in the input parameters will only have a minor effect on our Sharpe ratio estimation. The sensitivity with respect to noise in different input parameters is analyzed in more detail in section VI.

\section{B Equity premium estimation in other frameworks}

Of course, our estimator $\widehat{\gamma}_{\mathrm{EP}, \text { Merton }}$ for the equity premium is formally only justified in a Merton framework. Moving to more elaborated structural models of default usually has a significant impact on actual and risk neutral default probabilities. E.g. in a first-passage time framework with zero drift in the real world, actual default probabilities are twice as high as actual default probabilities in the Merton framework for the same parametrisation ('reflection principle').

Fortunately, our estimator does not only include the actual default probability but the difference between (the inverse of the cumulative normal distribution function of) the risk neutral and (the inverse of the cumulative normal distribution function of) the actual default probability. This difference can be shown to be very robust with respect to model changes. Intuitively, most models introduce features (e.g. first-passage mechanism, unobservable asset values) which have an effect on both actual and risk neutral default probability in the same direction. The difference between actual and risk neutral default probability therefore remains almost unchanged. The only parameter that solely has an effect on the actual default probability - without influencing the risk

\footnotetext{
${ }^{6}$ Here we are using the approximation CDS-spread $=\lambda^{Q} \cdot(1-\mathrm{RR})$. The risk neutral default intensity $\lambda^{Q}$ is derived from the risk neutral cumulative default probability via the relationship $Q^{\text {def }}(t, T)=1-e^{-\lambda^{Q} \cdot(T-t)}$.
} 
neutral default probability - is the Sharpe ratio.

The robustness with respect to model changes is analyzed in more detail in appendix A based on a first-passage time framework, strategic default frameworks and the Duffie/Lando (2001) framework with unobservable asset values. The correlation between asset and equity values in these frameworks is analyzed in appendix B.

\section{Data sources and descriptive statistics}

In each week our sample consists of the intersection of a) on-the-run companies in the CDX.NA.IG index $\left.{ }^{7}, b\right)$ the credit default swap (CDS) database of CMA (credit markets association) and c) the KMV EDF database. The Dow Jones CDX.NA.IG-index is the main CDS index in North America. It covers the 125 most liquid North American investment grade CDS. ${ }^{8}$ We used 5-year CDS spreads to derive risk neutral default probabilities because the 5-year maturity is the most liquid one. EDFs (expected default probabilities) from Moody's KMV data base were used as a proxy for the actual default probabilities and correlations with the S\&P500-index as a proxy for the correlations with the market portfolio. For all parameters, we used weekly data from the period from April 2003 until June 2007.9

Credit Default Swaps are OTC credit derivatives that have become widely popular over the last years with growth rates of over 100\% (nominal value) in 2005 and 2006 and total outstanding market volume of appr. $\$ 26$ trillion at the end of 2006 (ISDA (2006)). Their main mechanism is quite simple: The protection buyer periodically pays a predefined premium to the protection seller (usually quarterly). In case of a credit event, the protection seller has to cover the losses incurred on a predefined reference obligation, i.e. he has to pay an amount equal to the difference between the nominal and the current market value of the predefined reference obligation to the protection buyer. As usual, put into practice, things turn out to be more complicated: The credit event has to be precisely defined, a basket of reference obligations has to be specified ${ }^{10}$ and the term 'market value' at the time of default has to be clearly specified. As in most academic research (e.g. Berndt et.al (2005)), we will assume, that the extent of these specification does not have a sig-

\footnotetext{
${ }^{7}$ Our data sample start in $04 / 2003$ whereas the first CDX.NA.IG index starts in $10 / 2003$. For the dates before $10 / 2003$ we used the constituents of the CDX.NA.IG 1 index. The results do not materially differ if we start our sample period in $10 / 2003$.

${ }^{8}$ Although the CDX.NA.IG index is a North American index we will frequently refer to 'U.S.' since the vast majority of constituents is based in the U.S. Only two non-U.S.-based companies are in our sample (Bombardier and Alcan (both from Canada)).

${ }^{9}$ EDFs from KMV are only available on a monthly basis. We assumed EDFs to be constant within each month.

${ }^{10}$ Defining only a single reference obligation is not possible for practical reasons, which usually leads to a 'cheapestto-deliver' option for the protection buyer, who can normally choose which reference obligation to sell to the protection seller in case of a default.
} 
nificant value and therefore CDS can be prized as if these implicit options were not part of the game.

The 5-year CDS spreads (bid/ask/mid) used in our analysis were taken from Datastream. These data is compiled and provided by Credit Market Analysis (CMA) who collects CDS data from a range of market contributors from both buy- and sell-side institutions. Only dates with at least one trade or firm bid for the respective CDS are used to avoid potential errors from pure market maker data. We used CDS mid spreads for our analysis. Bid/ask-spreads served for consistency checks and sensitivity analysis. Since data quality is always an issue in over-the-counter markets we also used Bloomberg data sources as a quality check. The differences were minimal, probably also due to the fact that we have choosen the 125 most liquid counterparts in the market which should enhance data quality as well. The risk neutral default probability $\lambda_{Q}$ was derived by the approximation $P D^{Q}=\exp \left(-\frac{s}{L G D} \cdot T\right)$ out of the CDS spread s with maturity $T$ and the risk neutral loss given default $L G D$ (cf. Duffie/Singleton (2003)). A recovery rate $(1-L G D)$ of $45 \%$ was used and robustness tests were conducted.

Expected default frequencies (EDFs) from Moody's KMV data base were used as a proxy for the actual default probabilities. EDFs are default probabilities, which are based on a Merton-style structural framework, cf. Moody's KMV (2007). The calibration is, however, done more pragmatically based on a large set of historical data and on discriminant analysis. EDFs are widely used in the banking industry and also constitute a part of some of the internal rating systems of large banks. They have also been used in academic studies such as in Berndt et.al. (2005). We used 1-year EDFs (and the respective equivalent rating grades from Aaa to B3) and derived multi-year EDFs by Moody's cumulative default probabilites per rating grade. ${ }^{11}$ The cumulative default probabilities were determined via a logarithmic approach based on raw data from Moody's (2007). The resulting table of cumulative default probabilities can be found in Appendix C. The main advantage of EDFs compared to other ratings for our purpose is its link to market data: The current asset volatility and equity value are direct input parameters, therefore EDFs constitute a 'point-in-time' estimation of the current default probability. In contrast to EDFs, the ratings of the large rating agencies are defined as 'through-the-cycle'-ratings, which - in effect - results in different default probabilities for a specific rating grade dependent on the current overall economic outlook.

We used 3 -year weekly ${ }^{12}$ correlations between the reference entities share price returns and the S\&P-500 index. The share prices were taken from Datastream. We used median industry

\footnotetext{
${ }^{11}$ Cf. Appendix C for details. Elton et.al. (2001) use a similar approach based on transition matrices. We have opted for a direct cumulative estimation because of indications that rating migrations are non-Markovian. The differences are though minimial, robustness tests based on migration matrices are available on request.

${ }^{12}$ The calibration of correlations has a minor effect on the overall result, using 2-year or 1-year correlations did not alter results significantly.
} 


\begin{tabular}{rrrrrrr}
\hline Variable & $\mathrm{N}$ & Mean & Median & Std. dev. & 25th Perc & 75th Perc \\
\hline CDS mid & 24,785 & 54.53 & 39.80 & 58.41 & 25.50 & 61.00 \\
CDS offer & 24,785 & 56.76 & 42.00 & 59.31 & 27.20 & 63.50 \\
CDS bid & 24,785 & 52.37 & 37.70 & 57.69 & 23.70 & 59.00 \\
$\Delta$ (bid, offer) & 24,785 & 4.40 & 4.00 & 3.02 & 3.00 & 5.00 \\
EDF1 & 24,785 & $0.17 \%$ & $0.07 \%$ & $0.50 \%$ & $0.04 \%$ & $0.15 \%$ \\
EDF5 & 24,785 & $1.90 \%$ & $1.26 \%$ & $2.58 \%$ & $0.85 \%$ & $2.14 \%$ \\
$\rho$ & 24,785 & 0.52 & 0.53 & 0.08 & 0.46 & 0.59 \\
Implied market volatility & 24,785 & $17.14 \%$ & $16.31 \%$ & $2.36 \%$ & $15.43 \%$ & $18.80 \%$ \\
\hline
\end{tabular}

Table II:

\section{Descriptive statistics}

Descriptive statistics for input parameters. EDF1/EDF5: 1- and 5-year cumulative default probabilities based on KMV EDFs. $\rho$ : Equity/Market-correlation.

correlations since industry wide estimations of correlations have lower standard errors than a company by company estimation. This procedure also allowed to include companies without a 3 -year equity price history. The industry sector classification was based on the sub-indices of the CDX.NA.IG index.

Expected volatilities for the market portfolio were approximated by implied volatilities from the VIX term structure. Data was collected directly from the CBOE webpage ${ }^{13}$. We used implied volatilities based on mid options prices for maturities from 18-23 months which was the longest maturity bucket that was consistently available.

Our final data set consists of 24,785 date/company-combinations for which 5-year CDS spreads and EDFs were available. Table II gives an overview of the main input parameters. ${ }^{14}$

\section{Results}

Based on the data described in section III and the Merton estimator for the equity premium (7), the company Sharpe ratio (4) and the market Sharpe ratio (6) derived in section II, we estimate the implicit equity premium and company and market Sharpe ratios for each of the 24,785 observations. Table III provides the results on a yearly basis in column (3) to (8).

\footnotetext{
${ }^{13}$ Chicago Board Option Exchange, www.cboe.com/publish/vixtermstructure/vixtermstructure.xls.

${ }^{14}$ Based on 222 weeks in our sample period and 125 on-the-run constituents in the CDX.NA.IG index the theoretical maximum is 27,750 date/company-combinations. Therefore we have data available for appr. $90 \%$ of the theoretical maximum. This is probably also due to the fact that we used constituents of the most liquid CDS index and our sample period starts approximately at the same time when index trading - and therefore also liquidity - took off in the CDS markets.
} 


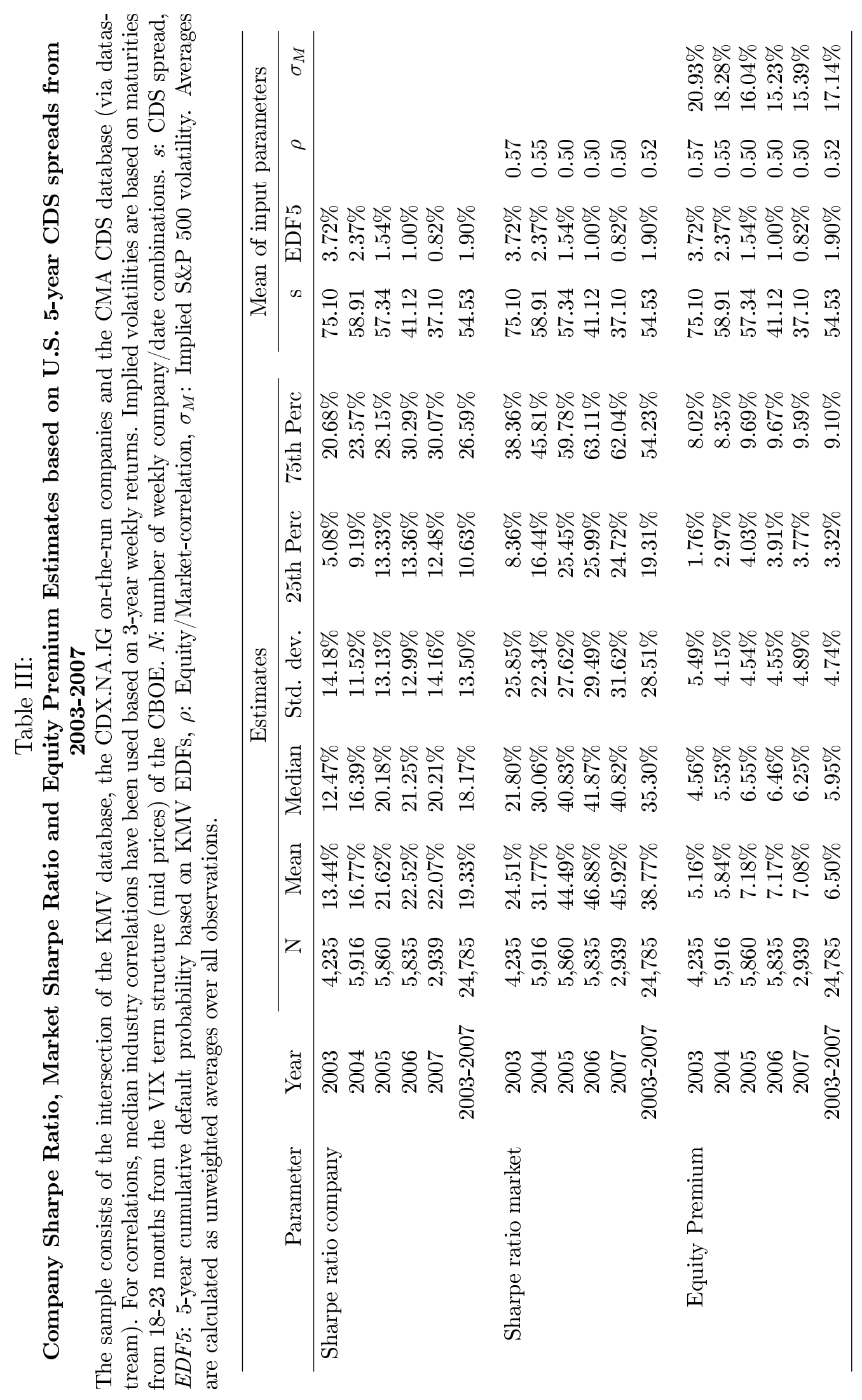


Our estimation yields an average equity premium of $6.50 \%$ for the U.S. market. The average company Sharpe ratio is $19.33 \%$ and the average market Sharpe ratio is $38.77 \%$. The median values are even lower with $5.95 \%$ for the equity premium and $18.17 \%$ and $35.30 \%$ for the company and market Sharpe ratio. We would already like to mention here that all these values are upper limits for the equity premium. This is due to some implicit conservative assumptions, especially concerning the part of the CDS spread which is due to credit risk (we assume 100\%) and the recovery rate (our assumption of $45 \%$ seems to be an upper limit), cf. section VI for details.

Looking at each year of our sample period separately shows a quite homogenous results: The implicit equity premium estimates range from $5.16 \%$ in 2003 to $7.18 \%$ in 2005 . The year 2005 also exhibits the largest one-year increase in the equity premium up $23 \%$ from $5.84 \%$ in 2004 . CDS premia were still as high in 2005 as in 2004 - especially due to an increase in spreads in the second quarter around the downgrades of Ford and General Motors - while EDFs were decreasing (2.37\% vs. $1.54 \%$ ) due to bullish equity markets and lower volatilities . Correlations were decreasing from 0.55 to 0.50 while implied volatilities decreased from $18.28 \%$ to $16.04 \%$ resulting in an almost unchanged term $\frac{\sigma_{M}}{\rho_{E, M}}$. It seems plausible to assume that these downgrades have led to an increase in risk aversion among market participants. We would like to point out that the implied equity premia also increased in the second quarter of 2007 at the beginning of the subprime crisis. Due to low levels in the first quarter of 2007, average estimates for the first half of 2007 are though almost the same than in 2006 ( $7.08 \%$ vs. $7.17 \%)$.

We would also like to point out to the fact that our results stem from very different conditions on the credit markets. Looking at CDS spreads, they averaged appr. $100 \mathrm{bp}$ at the beginning of our sample period and $75.10 \mathrm{bp}$ in the year 2003. This was accompanied by large EDFs (3.72\%), large correlations (0.57) and a high implied volatility (20.93\%). In the first half of 2007, spreads were less than half the spreads of $2003(37.10 \mathrm{bp})$, EDFs were less than a fourth of their 2003 levels $(0.82 \%$ vs. $3.71 \%)$, correlations were down to 0.50 and implied volatility was also significantly lower than in 2003 (15.39\% vs. 20.93\%). The fact that equity premium estimates were very similar throughout this time period indicates, that our estimates are not simply a result of a specific set of parameters but exhibit a certain robustness to changing market conditions. If at all, there seems to be a small tendency for equity premia to rise when credit markets are bullish (e.g. default rates and spreads decrease), although this is not or only partially true for the 2006 and 2007 period (from 2005 to 2006 Sharpe ratios increased but the implied equity premium decreased due to lower estimates for the implied volatility).

To get a first indication why these results are so robust we can decompose the spread into a part which is due to expected loss and a into a risk premium. In 2007, for example, the average cumulative actual default probability was $82 \mathrm{bp}$, i.e. the cumulative expected loss was $45 \mathrm{bp}$ (using 
$\mathrm{LGD}=55 \%$ ) and the per annum expected loss was appr. $9 \mathrm{bp}$. If we compare this expected loss to the average spread of $37 \mathrm{bp}$ we see that appr. $75 \%(28 \mathrm{bp} / 37 \mathrm{bp})$ of the spread is due to a risk premium. Doubling the risk premium while keeping the expected loss constant would require a $75 \%$ increase in the CDS spread. Doubling the risk premium by keeping the CDS spread constant is only possible with negative - and therefore unreasonable - EDFs. This intuitively indicates why our results are so robust. Small uncertainty or noise in the spread or the actual default probability simply does not significantly effect the results. We will discuss several robustness tests in more detail in section VI.

\section{Equity premium estimates for further maturities and from other markets}

We have expanded our analysis to maturities of 3, 7 and 10 years and to European and Asian reference entities, too. Maturities of 3, 5, 7 and 10 year are the standard maturities for which CDS indices are provided by 'markit'.

Using other maturities than 5 year serves several purposes: First, they offer a robustness check of our results from the previous section. On average, risk premia estimates based on 3,7 and 10 year maturities should not largely deviate from the results of the respective 5-year maturities. Second, these results could be used to identify a term structure of risk premia. We are not aware of any empirical analysis so far which has captured risk premia term structures. Therefore, comparison to other studies is of course limited but our results could offer a starting point for the discussion.

An application of the methodology to Europe and Asia also offers several perspectives. First, the results itself are of course interesting for an estimation of equity premia on these markets. Second, the results offer a good possibility to validate the robustness of the U.S.-results. If equity markets are globally integrated and risks are comparable, investors should demand a similar risk premium across different countries/regions. We would therefore expect equity premium estimates in a similar magnitude than based on U.S. data. Third, U.S., Europe and Asia offer a certain diversity concerning the loss experience and credit quality over our sample period. While the U.S. market was still in the aftermath of the Enron and Worldcom defaults at the beginning of our sample period and suffered the downgrades of Ford and GM in 2005, Europe did not suffer any comparable big-scale losses and had, on average, a better credit quality than the U.S. market. The Asian market did not suffer any unexpected large losses, too, but had on average a significantly lower credit quality than the U.S. market. These markets therefore offer a good opportunity to check if our estimator is robust with respect to these different credit market conditions. 
Again, our data sample consists of the intersection of the KMV database, the main CDS index for the respective markets and the CMA CDS database. We used the iTraxx Europe index for Europe and the iTraxx Asia ex Japan index for the Asian market. ${ }^{15}$ Only on-the-run companies were considered. The iTraxx Europe IG index consists of 125 investment grade constituents and is rolled over every 6 months. Index trading started later than in the U.S. (June 2004 vs. October 2003). The iTraxx Asia index started with 30 constituents in July 2004, it was later enlargerd to 50 constituents (effecive date $9 / 20 / 2005$ ). ${ }^{16}$ Due to the later start of index trading compared with the U.S. and data availability our sample period start at the beginning of 2004, so our sample includes the time period from January 2004 until June 2007. Again, we used the first series of the respective index to define on-the-run companies before the effective date of the first series. CDS spreads were based on the CMA database. For comparability, we included only weeks where spreads for all maturities (3, 5, 7 and 10 years) were available. Actual default probabilities were determined via EDFs from KMV. We used the same methodology as for the U.S. to transfer 1-year EDFs to cumulative default probabilities. We do though want to point out that this may be a source of inaccuracy since we assume the same migration probabilities than for the U.S. Especially for the Asian market, historical default data is rare. We are though not aware of any arguments why migration behaviour should be different for Europe or Asia compared to the U.S so we think that this approach gives estimates which are as close as possible to what market participants would assume. The DJStoxx 600 (Europe) and the S\&P Asia 50 (Asia) were used for an estimation of correlations. Median correlations per industry sector were again used for reasons of robustness. Implicit volatilities were calculated based on the VSTOXX Volatility sub-index 24 months. ${ }^{17}$ For the Asian market, implicit volatility indices are not available, therefore we used rolling 1-year historical volatilities of the S\&P 50 Asia index.

Table IV provides the results for the 3-, 5-, 7- and 10-year maturities for the U.S., Europe and Asia from 2004-2007. Please note that the 5-year results for the U.S. differ slightly from the previous section since only weeks where spreads for all maturities were available have been included in this data sample.

For the U.S., results based on 3-, 7-, and 10-year maturities are similar - but slightly smaller - than for the 5-year maturities. For the 2004-2007 period the equity premium estimation based

\footnotetext{
${ }^{15}$ There is also an iTraxx index covering Japan. We have choosen the iTraxx Asia ex Japan index to cover countries which seem to offer the best independent view compared with the U.S. and Europe. The biggest countries in the iTraxx Asia ex Japan are Korea, Hong Kong, Singapore, Malaysia, China and Taiwan. Together these countries offer a good perspective on a region where experience with corporate finance, derivative products and governance structures seem to be significantly different from the U.S. and Europe.

${ }^{16}$ After our sample period, effective $9 / 20 / 2007$, it was again enlargerd to 70 constituents.

${ }^{17}$ Implied volatiities for longer maturities are not available due to the lack of liquid option markets for longer maturities. Implied volatilities do though have the characteristic that they are less volatile for longer maturities. If at all, our results would therefore be even smoother if volatilities for longer maturities were available.
} 
on 5 -year maturities is $7.00 \%$ while the estimates for the 3-, 7- and 10-year maturities were $6.43 \%, 6.62 \%$ and $6.26 \%$ respectively. The market Sharpe ratio estimates range frome $39.32 \%$ $(\mathrm{T}=10)$ to $43.85 \%(\mathrm{~T}=5)$. All maturities show quite similar results for each year with equity premium estimates ranging from $4.80 \%(\mathrm{~T}=10,2004)$ to $7.33 \%(\mathrm{~T}=5,2005)$. All maturities exhibit an increase in the implied equity premium from 2004 to 2005 while the effect for other years is quite small. These results confirm our analysis for the equity premium from the last section.

For Europe, implied equity premium estimates are lower than for the U.S. They range from $5.03 \%(\mathrm{~T}=3)$ to $5.44 \%(\mathrm{~T}=5)$. Estimates for the 7-year maturity $(5.24 \%)$ and the 10-year maturity $(5.06 \%)$ yield similar results. Lower equity premia for Europe compared to the U.S. are consistent with both historical experience as well as evidence from other implied equity premium estimates. ${ }^{18}$ Market Sharpe ratios for Europe are also lower than for the U.S., ranging from $26.33 \%(\mathrm{~T}=3)$ to $28.39 \%(\mathrm{~T}=10)$ compared to a range of $39.32 \%$ to $43.85 \%$ for the U.S. This is also consistent with the theoretical argument that - from a global perspective - the U.S. market should be closer to the global market portfolio and therefore closer to the capital market line. The difference between estimates for the U.S. and Europe is especially pronounced in 2004 where implied equity premia estimates for Europa are as low as $1.87 \%(\mathrm{~T}=3)$. Excluding 2004 from the analysis does, however, still result in lower estimates for Europe compared to the U.S.

Average equity premia estimates for Asia are between the estimates from the U.S. and Europe. The lowest average estimates comes from the 10-year maturity $(5.60 \%)$ and the highest from the 3-year maturity $(6.50 \%)$ with estimates for the 5 - and 7 -year maturities in between $(6.21 \%$ and 5.84\%). The market Sharpe ratio estimates range from $35.54 \%$ to $41.40 \%$. Again, all yearly estimates are quite similar with the lowest estimate of $4.98 \%(\mathrm{~T}=10,2005)$ and the highest estimate of $7.63 \%$ ( $\mathrm{T}=3,2006)$. Interestingly, the increase in risk premia from 2004 to 2005 which occured both for the U.S. and for Europe was much less pronounced for Asia. Market Sharpe ratios in Asia were increasing from 2004 to 2005 - but significantly less than in the U.S. and Europe - while equity premia estimates were even decreasing due to decreasing volatilities.

All in all, the results based on 3-, 7- and 10-year maturities as well as the estimates for Europe and Asia confirm the results of the previous section and even lead to smaller equity premium estimates. Again, the resulting implicit equity premia are lower than based on historical estimates.

\footnotetext{
${ }^{18}$ For example, Claus/Thomas (2001) estimates an equity premium of $3.40 \%$ for the U.S. while estimates for the UK, France and Germany are $2.81 \%, 2.60 \%$ and $2.02 \%$.
} 


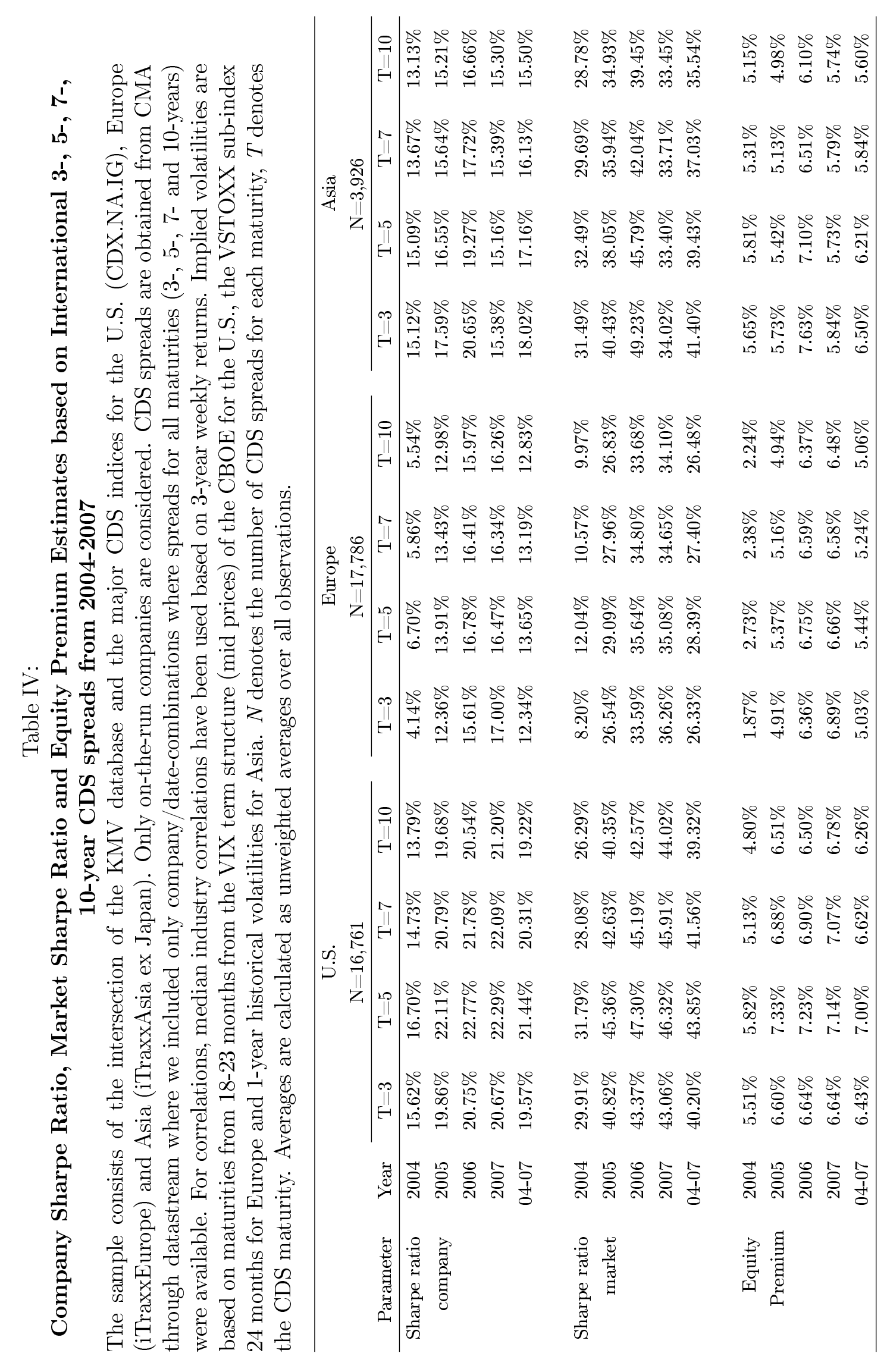




\section{Sensitivity analysis and robustness checks}

\section{A Sensitivity with respect to noise in input parameters}

In subsection II.B and appendix A we have shown that the results are quite robust to model changes. Besides misspecifying the model, noise in the input parameters poses another possible source of inaccuracy. We therefore tested the sensitivity of our results with respect to all input parameters. The results for the U.S. are shown in table V. ${ }^{19}$ We would especially like to point out two facts: First, parameter changes of $10 \%$ relative to its original value result in an equity premium of appr. 10\%/0.6 PP higher/lower for all parameters in our model. Second, the sensitivity is decreasing with increasing maturity. I.e., if input parameters have the same noise for all maturities then estimates based on 10-year maturities will be more accurate than estimates based on 3-year maturities. This can also be validated based on formula (8). Of course, these sensitivities must be analyzed in combination with the accuracy of the respective input parameters. I.e. a high sensitivity is worse if the respective input parameter can not be accurately determined, it is less harmful if the respective input parameter can be determined with very little noise. We will perform various kind of robustness tests in the following subsections.

\section{B Robustness: CDS-spread}

General remarks and bid/ask spreads: We have used several measures to ensure that our CDS data is not significantly biased in any direction. First, our datasource (CMA) is not based on a single market participant but based on data from several buy and sell side contributors. Second, we have compared our spreads to data from Bloomberg with no significant differences. Third, we have used constituents of the most liquid indices, which should enhance liquidity and data quality for the respective constituents. In addition our data sample should be easily comparable and reproducable and is not biased towards more recent dates.

Besides specific shortcomings of OTC markets, bid/ask spreads pose a natural noise in our data. We have used mean CDS spreads in our analysis. The average bid/ask-spread is only 4 bp in our sample which is probably also due to the fact that - in each week - we have only used the 125 most liquid CDS in the market. Using bid or ask quotes changes our average equity premium by less than $5 \% / 0.3 \mathrm{PP}$.

Portion of CDS spread attributable to credit risk: Some authors (e.g. Huang/Huang (2005) and Liu et.al. (2007) have argued, that especially for higher rating grades a significant part of the credit spread is not due to credit risk. Liu et.al. (2007) estimate that between $39 \%$

\footnotetext{
${ }^{19}$ Our robustness tests concentrate on the U.S. since the U.S. market provides the widest choice of studies and historical data for robustness tests. Sensitivities are similar for Europe and Asia and are available on request.
} 


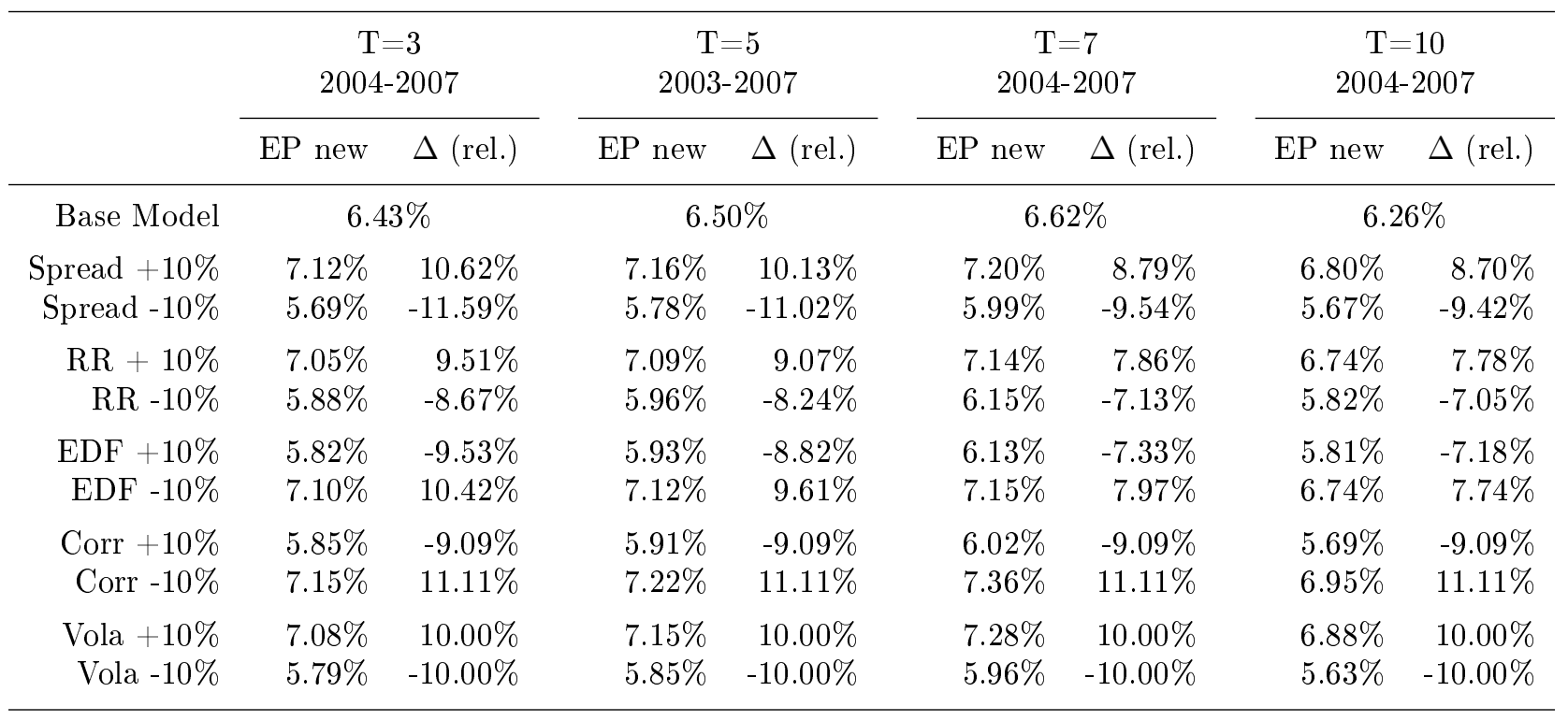

Table V:

Sensitivities of equity premium estimates for the U.S. market

Sensitivities of equity premium estimates for U.S. market. Base model denotes model with parameter choice as in section IV and V. $T=3, T=5, T=7$ and $T=10$ denote estimations based on different CDS maturities. EP new denotes equity premium estimate after change in input parameter as described in column (1). $\Delta$ (rel.) denotes relativ change of equity premium estimation relative to the base model. Spread: CDS spread for respective maturity, RR: Recovery rate, EDF: Expected default frequency, Corr: Asset/Market-Correlation, Vola: Implicit market volatility.

and $64 \%$ of the bond spread may be due to taxes. Although the tax effect on CDS is likely to be different, some part of the CDS spread may still be attributable to tax disadvantages compared to equity investments. Other research has focussed on the effect of liquidity risk on bonds and CDS. Bühler/Trapp (2008) extend the reduced-form credit risk model by Longstaff et.al. (2005) to incorporate liquidity risk in the CDS markets as well. They find that for CDS the liquidity risk portions accounts for appr. 5\% of the spread. In the academic literature, however, there does still not seem to be an agreement on the part of the CDS spread which is due to credit risk. In general, however, CDS are seen to be a rather pure measure of credit risk, at least in comparision with bond spreads. We do not aim to quantitatively account for a possible part of the spread which is not due to credit risk. We do only want to stress, that all these effects will lead to a decrease in the implicit equity premium since they result in a lower portion of the CDS spread attributable to credit risk. Therefore the derived equity premium of $6.50 \%$ is still valid as an upper limit for the equity premium. 


\section{Robustness: Recovery rate}

Based on Moody's (2007), the average recovery rate from 1982-2006 on senior unsecured bonds was $38 \%$ on an issuer-weighted basis, $37 \%$ on a value-weighted basis and $46 \%$ if each year (issuer-weighted) is given the same weight. The recovery rate volatility is significantly smaller than the default rate volatility, with a coefficient of variation of appr. $25 \%$ on a 1 -year basis compared to appr. $60 \%$ for the default probability. The interquartile range for a yearly issuer-weighted recovery rate is $39 \%-54 \%$ on a 1 -year basis and $43 \%-51 \%$ on a 5 -year average basis. Altman/Kishore (1996) also estimate an average recovery rate of $48 \%$ for senior unsecured bonds. Duffee (1999) and Driessen (2003) use a recovery rate of $44 \%$. Discussions with market participants indicated that a value of $40 \%$ for the risk neutral recovery rate is frequently used in practical applications.

Research on the recovery rates has soared over the last years, indicating, that recovery rates vary by industry sector and through the business cycle. E.g., Moody's (2007) indicates a significant negative correlation between realized recovery rate and realized default rate. In out-of-sample tests Chava et.al. (2006) also find indications that this relationship holds true for expected recovery rates as well. These findings may affect our results in three ways: First, some of the Sharpe ratio variation over time may also be due to time-varying recovery rates. Second, the overall level of the market Sharpe ratio may be biased if the average expected recovery rate for our time period was significantly different from historical averages. Chava et.al. (2006) set up a model, where the expected recovery rate can be explained by the coupon rate, the 3-month Treasury yield, the issue size and the seniority. Other covariates analyzed by Chava et.al. do not improve out-of-sample performance. Using their regression results for the expected actual recovery rate indicates again, that our recovery rate of $45 \%$ is an upper limit for the expected recovery rate. ${ }^{20}$ In addition, our sample consists of CDS with maturities up to 10 years from 2003-2007 which effectively means that recovery rates from 2003-2017 - e.g. a 15-year-horizon - are relevant for our averages. On the aggregate level, this should also help to mitigate some of the effects induced by time-varying recovery rates. Third, a countercyclical time-varying recovery rate results in risk neutral recovery rates which are lower than actual recovery rates. Again, our recovery rate of $45 \%$ is an upper limit for the recovery rate.

Altman/Kishore (1996) point out to the fact, that recovery rates vary not only by seniority but also by rating grade, i.e. higher recovery rates can be expected for higher rating grades. Their

\footnotetext{
${ }^{20}$ Based on Chava et.al. (2006), the expected recovery rate for senior unsecured bonds can be estimated as $0.5183+0.0182 \cdot$ couponrate $-0.0319 \cdot 3$ - month - Treasury - yield $-0.0332 \cdot \log ($ issuesize $)$, where coupon rate and Treasury yield are measured in percentage and the issue size is measured in $\$ 000$. Even a very conservative calibration for our purpose of (couponrate $=6,3-$ month-Treasury $=1$, issuesize $=\$ 10 \mathrm{~m}$ ) results in an expected recovery rate of appr. $45 \%$ (i.e. $46 \%$ ). Certainly, average coupon rates have been lower than $6 \%$, the average 3 -month Treasury yield has been higher than $1 \%$ and the average issue size for our sample has been higher than $10 \mathrm{~m}$, therefore the abovementioned calibration is conservative for our purpose.
} 
analysis is based on the rating grade one year prior to default. Based on Moody's (2006) (Exhibit 20) this effect does, however, diminish if the rating 3,4 or 5 years prior to default are considered. Given that defaults probabilities are increasing for investment grade ratings and we are looking at 5 -year CDS, default will happen on average in more than 3 years ahead ${ }^{21}$ so that the effect of the current rating is of minor importance.

All in all, a recovery rate of $45 \%$ used in our calculations seems to be an upper limit. Lower recovery rates would result in even lower Sharpe ratio estimates. Therefore our estimations poses an upper limit for the market Sharpe ratio.

\section{Robustness: Actual default probabilities}

Our primary source for the actual default probabilties are EDFs from KMV. These are point-in-time estimates for the real world default probability and therefore vary with the economic cycle. EDFs are frequently used by practitioners and academics and their performance has been analyzed in various studies (cf. Berndt et.al. (2005), Duffie et.al. (2007), Löffler (2004)). However, actual default probabilities seem to pose the largest possible source of inaccurarcy in our model. There are mainly three sources for possible inaccuracies: First, a bias may occur due to the use of an investment grade index. Second, one-year EDFs might be biased. Third, the determination of cumulative default probabilities form one-year EDFs may be inaccurate. We have conducted several robustness tests to address these issues.

The majority of traded CDS and bond volume is in the investment grade area. Based on the NASD/Bloomberg U.S. Corporate Bond Indices - which are comprised of the active fixed coupon bonds - more than $80 \%$ of the outstanding volume is in the investment grade area. Although numbers for the CDS market are not available, we do not expect large differences to the bond market. In addition, more than $95 \%$ of the investment grade reference entities based on the average agency rating did also have an investment grade rating based on EDFs, so differences are again minimal. There is a large number of studies which indicate that the non credit risk component is larger for higher rated obligors (cf. Amato (2005) and Elton et.al. (2001)). In this case, including sub-investment grade entities would even decrease our equity premium estimates.

We have performed several robustness checks for the actual default probability. First, we have used agencies ratings with the corresponding cumulative default probabilities. Unfortunately, these ratings are through-the-cylce estimates of the default probability. Using agencies ratings therefore requires the assumption that we cover a whole economic cylce. ${ }^{22}$ This assumption is probably most

\footnotetext{
${ }^{21}$ More precise, if $\tau$ denotes the default time and $T$ the maturity then $E[\tau \mid \tau<T]>3$.

${ }^{22}$ More exactly, it requires the assumption, that investors average expectations over our sample period correctly mirror an economic cycle.
} 
realistic for 5-year CDS - where we have covered the longest period from 2003-2007 including the high-expected default year 2003 - and for the longest maturity in our sample (10-year). We have averaged the ratings of Moody's, S\&P and fitch in our calculation and determined multi-period default probabilities based on appendix C. Only observations where at least one of the agencies ratings were available could be included which slightly decreased our data sample. Results are reported in table VI. For the 5-year CDS sample from 2003-2007 we estimate very similar default probabilities ( $1.77 \%$ vs. $1.65 \%)$ and equity premia (6.70\% vs. $6.66 \%)$. The estimated equity premium based on 10-year CDS spread are even lower (5.08\% (Agencies) vs. $6.35 \%$ (EDF)) but this may be due to a good credit environment from 2004-2007 - an effect which is certainly even more pronounced for shorter maturities.

Hazard rate models provide another robustness check for both 1-year and mulit-year default probabilities. There is a large literature on hazard rate models for the U.S. market, e.g. Shumway (2001) and Chava/Jarrow (2004). Unfortunately, most of these models only estimate one-year ahead default probabilities and can therefore only be used as a robustness check for one-year default probabilities. Löffler/Maurer (2008) estimate a discrete duration model for conditional default probabilities up to 5 years ahead. They use accounting covariates (e.g. EBIT, total assets) as well as market variables (e.g. return, volatility) similar to Shumway (2001) for default prediction. Details about their model can be found in appendix D.

For the estimates based on Löffler/Maurer (2008), we excluded financial services companies - which are excluded in their methodology - and all companies where Compustat data was not available. The results are reported in table VI. The estimates for the cumulative default probability are slightly higher resulting in slightly lower equity premia estimates, but both are very similar to the EDF model. Five year cumulative default probabilities are $1.89 \%$ for the Löffler/Maurer model compared to $1.79 \%$ for the EDF model with three year default probabilities of $0.72 \%$ compared to $0.59 \%$ for the EDF model. The resulting equity premia are $6.74 \%$ (5-year) and $6.11 \%$ (3-year) compared to $6.96 \%$ (5-year) and $6.61 \%$ (3-year) for the EDF model.

Of course, accuracies for estimating equity premia in our model should always be interpreted compared to alternative techniques for estimating equity premia. An inaccuracy of $10 \%$ in the average default probability results in an increase/decrease of our equity premium estimate by appr. $10 \% / 0.6 \mathrm{PP}$. This sensitivity is comparable to the sensitivity of the long-run growth rate in dividend discount models. ${ }^{23}$ In contrast to long-run growth rates we do though have (at least) partially objective criteria for default prediction. The sensitivity is also lower for higher rated obligors -

\footnotetext{
${ }^{23}$ Based on a Gordon model the equity premium estimate in a dividend discount model is $E P=g+d-r_{f}$ where $E P$ is the equity premium estimate, $g$ the growth rate of dividends, $d$ the dividend yield and $r_{f}$ the risk-free rate. If $d \approx r_{f}$ then the sensitivity with respect to $g$ is approx. 1 .
} 


\begin{tabular}{|c|c|c|c|c|c|c|c|c|c|}
\hline & & \multicolumn{2}{|c|}{$\begin{array}{c}\mathrm{T}=3 \\
2004-2007\end{array}$} & \multicolumn{2}{|c|}{$\begin{array}{c}\mathrm{T}=5 \\
2003-2007\end{array}$} & \multicolumn{2}{|c|}{$\begin{array}{c}\mathrm{T}=7 \\
2004-2007\end{array}$} & \multicolumn{2}{|c|}{$\begin{array}{c}\mathrm{T}=10 \\
2004-2007\end{array}$} \\
\hline & & $\begin{array}{r}\text { EDF } \\
\text { Model }\end{array}$ & $\begin{array}{r}\text { New } \\
\text { Model }\end{array}$ & $\begin{array}{r}\text { EDF } \\
\text { Model }\end{array}$ & $\begin{array}{r}\text { New } \\
\text { Model }\end{array}$ & $\begin{array}{r}\text { EDF } \\
\text { Model }\end{array}$ & $\begin{array}{r}\text { New } \\
\text { Model }\end{array}$ & $\begin{array}{c}\text { EDF } \\
\text { Model }\end{array}$ & $\begin{array}{r}\text { New } \\
\text { Model }\end{array}$ \\
\hline Agencies & $\mathrm{N}$ & 16,032 & 16,032 & 23,100 & 23,100 & 16,032 & 16,032 & 16,032 & 16,032 \\
\hline Rating & PD & $0.58 \%$ & $0.78 \%$ & $1.77 \%$ & $1.65 \%$ & $2.25 \%$ & $2.89 \%$ & $3.74 \%$ & $4.78 \%$ \\
\hline & $\mathrm{EP}$ & $6.52 \%$ & $4.29 \%$ & $6.70 \%$ & $6.66 \%$ & $6.71 \%$ & $5.26 \%$ & $6.35 \%$ & $5.08 \%$ \\
\hline Discrete & $\mathrm{N}$ & 10,078 & 10,078 & 14,700 & 14,700 & & & & \\
\hline Duration & $\mathrm{PD}$ & $0.59 \%$ & $0.72 \%$ & $1.79 \%$ & $1.89 \%$ & & & & \\
\hline Model & $\mathrm{EP}$ & $6.61 \%$ & $6.11 \%$ & $6.96 \%$ & $6.74 \%$ & & & & \\
\hline
\end{tabular}

Table VI:

Equity premium estimates based on different proxies for the real world default probability This table shows equity premium estimates where agencies ratings and default probabilities based on a discrete duration model have been used as proxies for the real world default probability. Agencies ratings are based on average ratings of Moody's, S\&P and fitch with corresponding cumulative default probabilities based on appendix C. The discrete duration model is based on Löffler/Maurer (2008) and excludes all financial services companies and all companies where the respective balance sheet and $\mathrm{P} \& \mathrm{~L}$ data was not available on Compustat. EDF Model denotes the model with EDFs as proxies for the real world default probability. New Model denotes the model with either PDs based on agencies ratings or based on Löffler/Maurer (2008). $N$ denotes the number of observations, $P D$ the average cumulative default probability and $E P$ the equity premium estimation. Equity premia estimations for the EDF model deviate from the previous sections due to a different sample size.

where realized default rates are usually very noisy - and higher for lower rated obligors - where defaults can be observed more frequently and default probabilities are thereofore more stable. In addition - in contrast to dividend/earnings forecasts - default predictions are not systematically biased.

\section{E Robustness: Asset Correlations}

We have used median industry equity correlations as a proxy for asset correlations. Theoretical evidence for our framework suggests, that equity correlations are very good proxies for asset correlations (cf. appendix B) but we have also performed robustness checks based on other measures of asset correlations.

Correlations enter our formular in the denominator (cf. (6)). If the estimation of the correlations is unbiased but exhibits noise, our estimator will therefore be upward biased. If, for example, the 'true' correlation would be 0.50 but due to noise we estimate (with equal probability) either 0.4 or 0.6 then the estimator is unbiased but the inverse of the correlation is upward biased (2.08 vs. 2.00). Therefore our estimations are upper limits for the true equity premium. 
As a robustness check used Basel-II-correlations instead of asset correlations. Asset correlations in the Basel-II-framework have been determined as a result of intensive debate between regulators, academics and practitioner, cf. BIS (2005), and are therefore a combined results of many studies on asset correlations. For large corporates, asset correlations in the Basel-II-framework are a function of the one-year actual default probability. It is important to notice that Basel-II uses asset/asset-correlations whereas we are interested in asset/market-correlations. In a single-factor framework like Basel-II, asset/market-correlations can be inferred from asset/asset-correlations by simply taking the square root of the asset/asset-correlations.

Average Basel-II-inferred correlations are 0.48, slightly smaller than the average median industry correlation of 0.52. Basel-II-correlations are though less dispersed.For investment grade ratings, Basel-II asset/asset-correlations are always between 0.20 and 0.24 (for large corporates) which is equivalent to asset/market-correlations between 0.45 and 0.49 . A lower dispersion leads to smaller averages since the asset/market-correlation enters our formula in the denominator, see (6). The resulting equity premium estimate is $6.73 \%$ (instead of 6.50\%). All in all, the results are very similar to the results based on equity-correlations.

\section{Conclusion}

In this paper, we have introduced a new framework for estimating the equity premium. We measure the risk attitude of investors based on credit valuations and transforms it to an equity premium via structural models of default. Intuitively, the CDS spread can be decomposed into two parts: First, a part which compensates for the expected loss. Second, a part which covers the risk premium demanded by investors. We separate these two parts and convert the risk premium into an equivalent equity premium. This approach offers a new line of thought for estimating the equity premium that is not directly linked to current methods.

We have theoretically analyzed the estimation of equity premia from credit valuations based on a simple Merton model and developed a simple estimator for the equity premium. This estimator only uses actual and risk neutral default probabilities, the maturity and equity correlations. We do neither have to calibrate a structural model nor do we have to estimate earnings or dividend growth. The theoretical results show an astonishing robustness of this simple estimator with respect to model changes. Although actual and risk neutral default probabilities are largely affected by model changes, the Merton estimator for the Sharpe ratio is only marginally affected.

CDS spreads in our model correspond to the market value of equity in dividend- and earnings-discount models and actual default probabilities correspond to earnings forecasts and long-run growth assumptions. While CDS spreads and the market value of equity can both be 
determined with little noise, the crucial inputs are earnings- and long-run growth forecasts in the dividend-/earnings-discount models and the actual default probability in our model. There are though two decisive advantages of estimating default probabilities compared to earnings forecasts and long-run growth rates: First, they only have to be estimated up to the maturity of the respective CDS. Second, there are (at least partially) objective criteria for estimating default probabilities.

An empirical analysis of 5-year CDS spreads from 2003-2007 of the constituents of the main CDS indices in North America, Europa and Asia yielded upper limits for the equity premium of $6.50 \%$ (North America), 5.44\% (Europe) and 6.21\% (Asia). Different CDS maturities (3-, 7-, 10-year) yield similar, but slightly lower, estimates for the equity premium and could provide an interesting insight on the term structure of risk premia. 


\section{A Robustness of Sharpe ratio estimator with respect to model changes}

In this section we will show that the Merton estimator for the Sharpe ratio is robust with respect to model changes. We will analyze the following frameworks: a first-passage-time framework based on Black/Cox (1976), a framework with unobservable asset values based on Duffie/Lando (2001) and - implicitly - all strategic default frameworks that yield a constant default barrier (e.g. Leland (1994), Leland/Toft (1996)).

First-passage time framework: In a first-passage time framework default occurs as soon as the asset value falls below the (non-stochastic, constant) default threshold. As in the Merton framework asset values $V_{t}$ are assumed to follow a geometric Brownian motion but default is now modelled as the stopping time $\tau:=\inf \left\{s>t ; V_{s} \leq L\right\}$, where $L \in \mathbb{R}$ denotes the default threshold. The actual $\left(P^{\text {def }}(t, T)\right)$ and risk neutral $\left(Q^{\text {def }}(t, T)\right)$ default probability can be calculated as

$$
\begin{aligned}
& P_{F P}^{\text {def }}(t, T)=\Phi\left(\frac{b-m^{P}(T-t)}{\sigma \sqrt{T-t}}\right)-e^{\frac{2 m^{P} b}{\sigma^{2}}} \Phi\left(\frac{b+m^{P}(T-t)}{\sigma \sqrt{T-t}}\right) \\
& Q_{F P}^{\text {def }}(t, T)=\Phi\left(\frac{b-m^{Q}(T-t)}{\sigma \sqrt{T-t}}\right)-e^{\frac{2 m^{Q_{b}}}{\sigma^{2}}} \Phi\left(\frac{b+m^{Q}(T-t)}{\sigma \sqrt{T-t}}\right)
\end{aligned}
$$

with $b=\ln \left(\frac{L}{V_{t}}\right), m^{P}=\mu-\frac{1}{2} \sigma^{2}, m^{Q}=r-\frac{1}{2} \sigma^{2}$ and $\sigma=\sigma_{V}$. If either the actual or the risk neutral drift is zero, then - based on the reflection principle - the respective default probability simply equals twice the default probability of the Merton framework.

Framework with unobservable asset values (Duffie/Lando (2001): The first-passage time framework has been extended in numerous ways to better reflect the default term structure observed in the markets. These extensions include jumps in the asset value process (Zhou (1997)), an unobservable default barrier (Finger et.al. (2002)) and unobservable asset values (Duffie/Lando (2001)). We choose the Duffie/Lando model for our analysis as it is the only structural model consistent with reduced form credit pricing. ${ }^{24}$ In addition, the Duffie/Lando model incorporates a sophisticated structural model of default (i.e. a strategic setting of the default barrier based on the asset value process, tax shield and insolvency costs) and - given an appropriate calibration - results in realistic default intensities for short and long term maturities.

\footnotetext{
${ }^{24}$ The Duffie/Lando model is the only structural model so far that yields a default intensity. Defaults in a Merton framework cannot be described by default intensity processes, since the probability of a default from $t$ (today) until $t+\delta t$ is always zero or one for a sufficient small $\delta t$. A default intensity does also not exist in the Zhou (1997) framework, since the default time cannot be represented by a totally inaccessible stopping time (which is a consequence of the fact, that the default barrier may be hit/crossed by the normal diffusion process with positive probability), cf. Duffie/Lando (2001) for details.
} 
In the Duffie/Lando framework the asset value is modelled as a geometric Brownian motion with initial value $z_{0}:=\ln \left(V_{0}\right)$, volatility $\sigma$ and drift $m^{P}:=\mu-\delta$ (actual drift) and $m^{Q}:=r-\delta$ (risk neutral drift) respectively, where $\delta$ denotes the constant payout rate. Like in the classical first passage time framework, default is modelled as the stopping time $\tau:=\inf \left\{s>t ; V_{s} \leq L\right\}$, where $L \in \mathbb{R}$ denotes the default threshold. In contrast to the classical first passage time framework, investors are not able to observe the asset process directly. Instead they receive imperfect information $Y\left(t_{i}\right):=\ln \left(\widehat{V_{t_{i}}}\right)=\ln \left(V_{t_{i}}\right)+\alpha U_{t_{i}}$ at the times $t_{i}, 1 \leq i \leq n$, where $U\left(t_{i}\right)$ is normally distributed and independent of $B_{t_{i}}$ and $\alpha$ is a parameter specifying the degree of noise in the information received by the bond/CDS investors. Therefore, the information filtration given to the bond/CDS investors is ${ }^{25} \mathcal{H}_{t}=\sigma\left(\left\{Y\left(t_{i}\right), \ldots, Y\left(T_{n}\right), 1_{\tau \leq s}: 0 \leq s \leq t\right\}\right)$. As in Duffie/Lando (2001), we will focus on the case, where investors receive simply one noisy information about the asset value. Under these assumptions the conditional density $g\left(x \mid Y_{t}, z_{0}, t\right)$ of the asset value $V_{t}$ conditional on the noisy information $Y_{t_{i}}$ and survival up to time $t$ can be explicitly calculated (cf. Duffie/Lando (2001) for details).

The calculation of the cumulative default probabilities requires a weighted application of (9) and (10) over all possible asset values $V_{t}$, where the weight is - roughly speaking - the probability of the asset value $V_{t}^{26}$, i.e.

$$
\begin{aligned}
P_{D L}^{\text {def }}(t, T) & =\int_{L}^{\infty} \underbrace{P_{F P}^{\text {def }}(t, T, x)}_{\mathrm{PD}(\text { first passage time }) \text { if } \mathrm{V}_{\mathrm{t}}=\mathrm{x}} \underbrace{g^{P}\left(x \mid Y_{t}, z_{0}, t\right)}_{\text {Prob., that } \mathrm{V}_{\mathrm{t}}=\mathrm{x}} d x \\
Q_{D L}^{\text {def }}(t, T) & =\int_{L}^{\infty} Q_{F P}^{\text {def }}(t, T, x) g^{Q}\left(x \mid Y_{t}, z_{0}, t\right) d x
\end{aligned}
$$

where $P_{F P}^{\text {def }}(t, T, x) / Q_{F P}^{\text {def }}(t, T, x)$ denotes the actual/risk neutral probability that an asset value process starting in $t$ at $V_{t}=x$ will fall below the default barrier up to time $T$ (cf. (9)and (10)) and $g^{P} / g^{Q}$ is the actual/risk neutral conditional density of the asset value at $t$ given the filtration $\mathcal{H}_{t}{ }^{27}$

We will now introduce an adjustment factor which captures the difference between the Merton estimator for the Sharpe ratio and the 'true' Sharpe ratio. This adjustment factor will be defined by

$$
\frac{\mu_{M}-r}{\sigma_{M}}=\gamma_{\text {Merton }} \cdot A F
$$

\footnotetext{
${ }^{25}$ Of course, all investors can obvserve whether a default has already occured.

${ }^{26}$ Of course the probability of a single value $V_{t}$ will be zero for non-degenerated parameter choices, since we operate in a continuous setting. We will still use this informal notation to allow for a better understanding.

${ }^{27}$ Please note that the conditional density itself is dependent on the respective measure (actual/risk neutral). Intuitively, the investor in the Duffie/Lando framework 'processes' two pieces of information: First, the noisy information about the asset value. Second, the fact that no default has occured up to time $t$. While the first piece of information is the same in both actual and risk neutral world, the second differs.
} 
where

$$
\gamma_{\text {Merton }}=\frac{\Phi^{-1}\left(Q_{D L}^{\text {def }}(t, T)\right)-\Phi^{-1}\left(P_{D L}^{d e f}(t, T)\right)}{\sqrt{T}} \cdot \frac{1}{\rho_{V, M}}=\gamma\left(V_{t} / L, \mu, r, \delta, \sigma, \alpha, t, T\right)
$$

is a function of all parameters in the Duffie/Lando framework and therefore

$$
A F=A F\left(V_{t} / L, \mu, r, \delta, \sigma, \alpha, t, T\right)
$$

is also a function of the same parameters. The basic idea is now to substitute $V_{t} / L$ by the actual default probability $P D^{P}$. Fixing all other parameters except $V_{t} / L$, different values for $V_{t} / L$ simply result in different actual default probabilities $P D^{P}$, i.e. we can write our adjustment factor as

$$
A F=A F\left(P D^{P}, \mu, r, \delta, \sigma, \alpha, t, T\right)
$$

As a special case, $\alpha=0 \%, \delta=0 \%$ yields the classic first-passage time framework. Strategic default frameworks where the default barrier is endogeneously determined but constant are also captured since we will simply cover any reasonable parameter combinations. I.e., for any default barrier $L$, we will cover all combinations which result in a rating between $\mathrm{Aa}$ and $\mathrm{B}$ and where the other parameters are within a reasonable range, see discussion below.

We have numerically evaluated (15) for all reasonable combinations of input parameters. ${ }^{28}$ The calculation was carried out in four steps: In the first step, a combination of a specific rating grade and all parameters from the Duffie/Lando framework excluding the asset value $V_{t}$ was choosen. Please note, that this also involves the specification of the asset Sharpe ratio in order to determine the real world drift of the asset value process. Then, based on (11), the asset value $V_{t}$ was numerically determined as to result in the cumulative actual default probability for the respective rating category. Given the asset value $V_{t}$ and the other parameters choosen in the first step, a straight forward application of (12) based on risk neutral parameters was used to determine the risk neutral default probability. In the fourth step, the Merton estimator (14) was calcualted based on these model-based actual and risk neutral default probabilities. Comparison with the asset Sharpe ratio specified in step 1 yields the adjustment factor (based on (13)). These four steps

\footnotetext{
${ }^{28}$ Input parameters used were: $\sigma: 3 \%-30 \%$ (the $5 \%$ and $95 \%$ quantile for the asset volatility from KMV was $6 \%$ and $25 \%$ respectively), Sharpe ratio of the asset value process: $10 \%$ to $40 \%$ (The market Sharpe ratio is usually assumed to be anywhere between $20 \%$ and $50 \%$, due to a correlation of lower than 1, the asset Sharpe ratio should be smaller), $m: 0 \%-5 \%$ ( $m<0$ would imply, that the payout rate is larger than the risk free rate, $\mathrm{m}=5 \%$ was choosen as an upper limit to reflect (almost) zero payout at a risk free interest rate of $5 \%$.), $\alpha: 0 \%-30 \%(\alpha=0 \%$ reflects the classical first passage model with observable asset values, Duffie/Lando use $10 \%$ as a standard value, the upper limit of $30 \%$ is also based on Duffie/Lando(2001)), $\widehat{V}_{t}=V_{0}$ was implicitly choosen to result in the desired rating grade from Aa to B. The case $\widehat{V}_{t}>V_{0}$ and $\widehat{V}_{t}<V_{0}$ was also analyzed, the results barely differ from the case $\widehat{V}_{t}=Z_{0}$ and are available upon request. The correlation coefficient $\rho_{V, M}$ is already captured by the asset Sharpe ratio (which is the product of market Sharpe ratio and $\left.\rho_{V, M}\right)$.
} 
were repeated for all reasonable parameter combinations.

The results are reported in table VII based on three scenarios: Scenario 1 restricts the asset volatility to be larger or equal to $10 \%$. Asset volatilities below $10 \%$ are usually only observed for financial services companies. Scenario 2 captures all parameter combinations where the average default time is larger than 0.5 time the maturity. This scenario is based on a usual assumption for investment grade entities, i.e. that real world annual conditional default probabilities are an increasing function of the maturity. Scenario 3 sets the risk neutral drift of the asset value relative to the default boundary to zero. This captures the assumption of constant expected leverage. These three scenarios were designed to capture realistic parameter combinations.

Based on a 5-year maturity, the adjustment factor for investment grade entities is always between 0.85 and 1.27 in scenario 1 , between 0.82 and 1.24 in scenario 2 and between 0.82 and 1.08 in scenario 3. If one does not restrict the parameter combination to one of these scenarios, very large adjustment factors may occur for some very rare parameter combination. These are combinations of a very high asset value drift combined with a low volatility. In these cases, default either happens 'very early' or never at all. Then, the difference between risk neutral and actual default probability is relatively small because the investor is only exposed to systematic risk for a very short time period, afterwards the large drift and low volatility result in very low default probabilities. Apart from these unrealistic cases, the adjustment factors are very close to one and the estimator is therefore robust with respect to model changes. The results are similar for maturities of 3,7 and 10 years.

\section{B Correlation between asset and equity returns}

In this appendix, we will show that the correlation between asset returns and market returns in the Merton framework as well as in the Duffie/Lando framework is approximately equal to the correlation between equity returns and market returns. Since covariance matrices are always positiv semidefinit, it is sufficient to show, that the correlation between asset returns and equity returns is approximately one. ${ }^{29}$ The economic reason for a correlation of one between asset and equity values is quite simple: As equity is modeled in both frameworks as a deep-in-the-the-money ${ }^{30}$ call option on the companies assets ${ }^{31}$, the sensitivity of the option with respect to the asset value is almost linear (i.e. the delta of the option is almost one and therefore gamma is close to zero). A linear

\footnotetext{
${ }^{29}$ Since the covariance matrix is positv semidefinit, it has a non-negative determinant. The determinant of the covariance matrix equals $\sigma_{1}^{2} \sigma_{2}^{2} \sigma_{3}^{2} \cdot\left(1+2 \rho_{1,2} \rho_{1,3} \rho_{2,3}-\rho_{1,2}^{2}-\rho_{1,3}^{2}-\rho_{2,3}^{2}\right)$. If $\rho_{1,2}=1$, it follows that $2 \rho_{1,3} \rho_{2,3}-\rho_{1,3}^{2}-\rho_{2,3}^{2}=$ $-\left(\rho_{1,3}-\rho_{2,3}\right)^{2} \geq 0$ and therefore $\rho_{1,3}=\rho_{2,3}$. We have also directly simulated the difference between the correlation between equity and market values and asset and market values. The results confirm the analysis in this appendix.

${ }^{30}$ Of course, this option is not by definition deep-in-the-money but rather depends on the 'closeness' of the asset value to the default barrier. Looking at investment grade ratings, the maximum one-year default probability is approximately $0.4 \%$ and the maximum 10 -year cumulative default probability is approximately $8 \%$. This motivates the use of the term 'deep-in-the-money'.

${ }^{31}$ The sort of option is of course different in both frameworks: a plain vanilla european call option in the Merton framework and a knock-out option in the Duffie/Lando framework.
} 
Table VII:

\begin{tabular}{|c|c|c|c|c|c|c|c|}
\hline \multirow[b]{2}{*}{ Maturity } & \multirow[b]{2}{*}{ Rating } & \multicolumn{2}{|c|}{$\sigma \geq 10 \%$} & \multicolumn{2}{|c|}{ Default Timing $\geq 50 \% \cdot T$} & \multicolumn{2}{|c|}{ Risk-neutral drift $=0 \%$} \\
\hline & & $\operatorname{Min}_{A F}$ & $\operatorname{Max}_{A F}$ & $\operatorname{Min}_{A F}$ & $\operatorname{Max}_{A F}$ & $\operatorname{Min}_{A F}$ & $\operatorname{Max}_{A F}$ \\
\hline \multirow[t]{4}{*}{3} & $\mathrm{Aa}$ & 0.77 & 1.07 & 0.73 & 1.20 & 0.73 & 1.03 \\
\hline & A & 0.78 & 1.10 & 0.73 & 1.23 & 0.73 & 1.04 \\
\hline & Baa & 0.79 & 1.14 & 0.74 & 1.21 & 0.74 & 1.06 \\
\hline & IG (Total) & 0.77 & 1.14 & 0.73 & 1.23 & 0.73 & 1.06 \\
\hline \multirow[t]{4}{*}{5} & Aa & 0.85 & 1.14 & 0.82 & 1.24 & 0.82 & 1.05 \\
\hline & A & 0.86 & 1.19 & 0.82 & 1.23 & 0.82 & 1.06 \\
\hline & Baa & 0.87 & 1.27 & 0.84 & 1.21 & 0.84 & 1.08 \\
\hline & IG (Total) & 0.85 & 1.27 & 0.82 & 1.24 & 0.82 & 1.08 \\
\hline \multirow[t]{4}{*}{7} & Aa & 0.90 & 1.22 & 0.87 & 1.23 & 0.87 & 1.06 \\
\hline & A & 0.90 & 1.29 & 0.87 & 1.20 & 0.87 & 1.07 \\
\hline & Baa & 0.91 & 1.41 & 0.89 & 1.18 & 0.89 & 1.11 \\
\hline & IG (Total) & 0.90 & 1.41 & 0.87 & 1.23 & 0.87 & 1.11 \\
\hline \multirow[t]{4}{*}{10} & $\mathrm{Aa}$ & 0.93 & 1.34 & 0.91 & 1.23 & 0.91 & 1.07 \\
\hline & A & 0.94 & 1.45 & 0.92 & 1.22 & 0.92 & 1.10 \\
\hline & Baa & 0.95 & 1.62 & 0.94 & 1.17 & 0.94 & 1.14 \\
\hline & IG (Total) & 0.93 & 1.62 & 0.91 & 1.23 & 0.91 & 1.14 \\
\hline All & IG (Total) & 0.77 & 1.62 & 0.73 & 1.24 & 0.73 & 1.14 \\
\hline
\end{tabular}

\section{Adjustment factors in the Duffie/Lando framework}

Minimum and maximum adjustment factors for investment grade ratings and maturities from 3 to 10 years. $A F_{\text {Min }}$ and $A F_{\text {Max }}$ denote minimum and maximum adjustment factors for the respective scenario. The scenario ' $\sigma \geq 10 \%$ ' represents non-financials since asset values below $10 \%$ are usually only observed for financial services companies. The scenario 'Default Timing $\geq 50 \% \cdot T$ ' captures all parameter combinations where the average default time conditional on default up to time $T(\tilde{\tau}:=E[\tau \mid \tau \leq T])$ was larger than $0.5 \cdot T$. A usual assumption for investment grade entities is an increasing real world default probability which results in $\tilde{\tau}>0.5 \cdot T$. The scenario 'Risk-neutral drift $=0 \%$ ' captures a frequent assumption of zero asset value drift in the risk neutral world, i.e. the expected leverage $V_{t} / L$ is assumed to be constant. 
relationship between two random variables in turn implies a correlation of one. The correlation will be the smaller, the less linear the relationship is, i.e. the higher the default probability (and therefore the less in-the-money the option) and/or the higher the effect of other input parameters that lead to non-linearities with respect to the asset value (e.g. taxes, insolvency costs in the Duffie/Lando framework).

The determination of correlations is straightforward: First, a rating grade from Aa to B is choosen. Second, all reasonable combinations of input parameters - without the asset value - were depicted. In the third step the asset value was choosen as to yield the cumulative default probability of the respective rating grade choosen in the first step (cf. appendix $\mathrm{C}$ for the cumulative default probabilities). In the last step, the correlations for these parameter combinations were numerically evaluated with a Monte Carlo simulation. The minimum correlation for each rating grade was plotted in figure 2. The minimum correlation is always larger than 0.99 for investment grade obligors and larger than 0.96 for non-investment grade obligors.

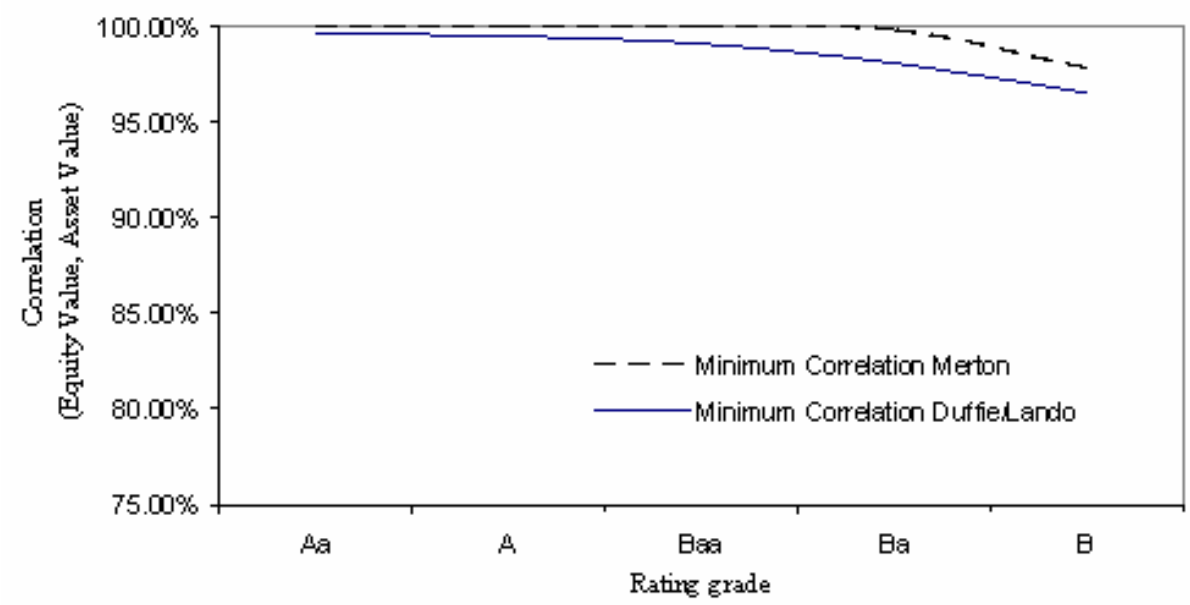

Figure 2: Correlation between equity and asset value in the Merton and Duffie/Lando framework. Parameter combinations for calculating the minimum: $T$ (maturity):3-10y, $\sigma: 3 \%-30 \%$, company Sharpe ratio: $10 \%-40 \%$, risk neutral asset growth rate after payouts: $0 \%-5 \%, \alpha$ (asset value uncertainty): $0 \%-30 \%, T_{1}$ (time since last certain asset value information): $0 y-3 y$, other parameters: $r=6 \%$, default barrier $=100, V_{t}$ choosen to fit target actual default probability for respective rating grade. 


\section{Mapping of Moody's rating grades to default probabilites}

For the mapping of Moody's rating grades to default probabilities and one-year EDFs to mulit-year EDFs, we used the raw data provided by Moody's (2007). We used a log-linear relationship to calibrate the default probabilities, i.e. we performed the regression

$$
\ln (P D)=\beta_{1}+\beta_{2} \cdot N R G,
$$

where NRG denotes the numerical rating grade ranging from 1 (Aaa) to 16 (B3) and PD denotes the historical default probabilities per rating grade. ${ }^{32}$ The resulting cumulative default probabilities are shown in table VIII.

\begin{tabular}{rrrrrrrrrrrr}
\hline & \multicolumn{10}{c}{ Maturity } \\
\cline { 2 - 13 } Rating & 1 & 2 & 3 & 4 & 5 & 6 & 7 & 8 & 9 & 10 \\
\hline Aaa & 0.001 & 0.006 & 0.019 & 0.041 & 0.071 & 0.094 & 0.114 & 0.125 & 0.135 & 0.148 \\
Aa1 & 0.002 & 0.011 & 0.032 & 0.065 & 0.108 & 0.143 & 0.173 & 0.190 & 0.205 & 0.224 \\
Aa2 & 0.004 & 0.018 & 0.052 & 0.103 & 0.166 & 0.218 & 0.261 & 0.287 & 0.310 & 0.339 \\
Aa3 & 0.007 & 0.032 & 0.085 & 0.163 & 0.255 & 0.331 & 0.394 & 0.434 & 0.470 & 0.512 \\
A1 & 0.013 & 0.055 & 0.139 & 0.256 & 0.392 & 0.502 & 0.596 & 0.657 & 0.712 & 0.775 \\
A2 & 0.024 & 0.095 & 0.228 & 0.404 & 0.601 & 0.763 & 0.900 & 0.995 & 1.078 & 1.173 \\
A3 & 0.045 & 0.164 & 0.373 & 0.637 & 0.922 & 1.159 & 1.360 & 1.506 & 1.633 & 1.774 \\
Baa1 & 0.083 & 0.285 & 0.611 & 1.004 & 1.416 & 1.760 & 2.056 & 2.278 & 2.475 & 2.683 \\
Baa2 & 0.152 & 0.493 & 1.002 & 1.583 & 2.173 & 2.674 & 3.107 & 3.447 & 3.750 & 4.058 \\
Baa3 & 0.279 & 0.855 & 1.642 & 2.496 & 3.335 & 4.063 & 4.695 & 5.217 & 5.681 & 6.139 \\
Ba1 & 0.514 & 1.482 & 2.691 & 3.934 & 5.120 & 6.172 & 7.095 & 7.894 & 8.607 & 9.286 \\
Ba2 & 0.946 & 2.569 & 4.411 & 6.202 & 7.858 & 9.376 & 10.722 & 11.946 & 13.041 & 14.046 \\
Ba3 & 1.741 & 4.452 & 7.229 & 9.778 & 12.061 & 14.243 & 16.204 & 18.076 & 19.759 & 21.247 \\
B1 & 3.204 & 7.716 & 11.847 & 15.414 & 18.512 & 21.638 & 24.488 & 27.354 & 29.936 & 32.139 \\
B2 & 5.896 & 13.373 & 19.417 & 24.301 & 28.413 & 32.871 & 37.007 & 41.392 & 45.356 & 48.615 \\
B3 & 10.850 & 23.178 & 31.823 & 38.310 & 43.611 & 49.936 & 55.926 & 62.635 & 68.719 & 73.538 \\
\hline
\end{tabular}

Table VIII:

Cumulative default probabilities for Moody's ratings in percent

Cumulative default probabilities based on Moody's (2007) and based on a log-approach $\ln (P D)=\beta_{1}+\beta_{2} \cdot N R G$, where NRG denotes the numerical rating grade ranging from 1 (Aaa) to 16 (B3).

\footnotetext{
${ }^{32}$ The log-approach is a common approach for the calibration of default probabilities (cf. for example Bluhm et.al (2003)).
} 


\section{Discrete duration model based on Löffler/Maurer (2008)}

The model of Löffler/Maurer (2008) estimates cumulative default probabilities via a discrete duration model. The hazard function $h(t)$ is defined via

$$
h(t+k)=P\left(Y_{t+k, t+k+1}=1 \mid Y_{t+k-1, t+k}=0, X_{t}\right)=\frac{1}{1+\exp \left(-\alpha_{k}-\beta_{k} X_{t}\right)}
$$

where $Y_{t+k, t+k+1} \in\{0,1\}$ is the default indicator for the period $(t+k, t+k+1]$ and $X_{t}$ denotes the vector of covariates. $\left(\alpha_{k}, \beta_{k}\right)$ is the vector of coefficient estimates, see table IX below. Multi-period default probabilities can be derived via

$$
P\left(Y_{t, t+k}=1\right)=1-\prod_{j=0}^{k-1}(1-h(t+j)) .
$$

\begin{tabular}{rrrrrr}
\hline & \multicolumn{5}{c}{ Prediction Horizon in Years } \\
\cline { 2 - 6 } & 1 & 2 & 3 & 4 & 5 \\
\hline L & $4.89^{* * *}$ & $2.97^{* * *}$ & $2.41^{* * *}$ & $1.49^{* *}$ & $0.99^{*}$ \\
& $(0.53)$ & $(0.41)$ & $(0.39)$ & $(0.46)$ & $(0.48)$ \\
EBIT/TA & -1.85 & 0.95 & -0.24 & 1.86 & 2.23 \\
& $(1.06)$ & $(1.16)$ & $(1.29)$ & $(1.48)$ & $(1.68)$ \\
EBIT/XINT & $-0.3^{* *}$ & $-0.33^{* * *}$ & $-0.19^{* *}$ & $-0.29^{* *}$ & $-0.31^{* * *}$ \\
& $(0.1)$ & $(0.08)$ & $(0.07)$ & $(0.09)$ & $(0.09)$ \\
SIZE & $-0.18^{* * *}$ & $-0.2^{* * *}$ & $-0.19^{* * *}$ & $-0.22^{* * *}$ & $-0.21^{* * *}$ \\
& $(0.05)$ & $(0.05)$ & $(0.05)$ & $(0.05)$ & $(0.06)$ \\
dTA & $1.09^{* *}$ & $1.13^{* * *}$ & $1.12^{* *}$ & $1.17^{*}$ & $1.37^{* *}$ \\
& $(0.39)$ & $(0.34)$ & $(0.4)$ & $(0.5)$ & $(0.45)$ \\
RET & $-1.67^{* * *}$ & $-0.65^{* * *}$ & -0.29 & -0.24 & -0.11 \\
& $(0.31)$ & $(0.18)$ & $(0.16)$ & $(0.19)$ & $(0.2)$ \\
VOLA & $4.7^{* * *}$ & $4.39^{* * *}$ & $3.42^{* *}$ & 0.66 & 0.33 \\
& $(1.01)$ & $(1.11)$ & $(1.07)$ & $(1.36)$ & $(1.39)$ \\
Constant & $-9.05^{* * *}$ & $-7.53^{* * *}$ & $-7.08^{* * *}$ & $-6.47^{* * *}$ & $-6.12^{* * *}$ \\
& $(0.54)$ & $(0.49)$ & $(0.44)$ & $(0.5)$ & $(0.53)$ \\
\hline
\end{tabular}

Table IX:

Coefficients for discrete duration model based on Löffler/Maurer (2008)

This table contains the coefficient estimates from Löffler/Maurer (2008). L: leverage (= Total debt / (Total debt + Marketcap)), XINT: interest expenses, SIZE: log of the market cap divided by the S\&P-500 market capitalization, $d T A$ : one-year asset growth, RET: 12-month cumulative equity return, VOLA: 12-month monthly equity volatility. 


\section{References}

[1] Altman, E.I. and Kishore, V.M., 1996, Almost Everything You Wanted to Know about Recoveries on Defaulted Bonds, Financial Analysts Journal 52(6), 57-64.

[2] Agrawal, D., Arora, N., and Bohn, J., 2004, Parsimony in Practice: An EDF-based Model of Credit Spreads, Moody's KMV.

[3] Amato, J. and Remolona,E., 2005, The Pricing of Unexpected Credit Losses, BIS Working Papers.

[4] Berndt, A., Douglas, R., Duffie,D., Ferguson, M., and Schranz, D., 2005, Measuring default risk premia from default swap rates and EDFs, BIS Working Papers, No 173.

[5] BIS, 2005, An Explanatory Note on the Basel II IRB Risk Weight Functions, BIS.

[6] Black, F. and Cox, J., 1976, Valuing corporate securities: Some effects of bond indenture provisions, Journal of Finance, 351-367.

[7] Black, F. and Scholes, M., 1973, The Pricing of Options and Corporate Liabilities, Journal of Political Economy.

[8] Bluhm, C., Overbeck, L., and Wagner, C., 2003, An Introduction to Credit Risk Modeling, Chapman \& Hall.

[9] Bohn, J., 2000, An Empirical Assessment of a Simple Contingent-Claims Model for the Valuation of Risky Debt, Journal of Risk Finance, p. 55-77.

[10] Chava, S. and Jarrow, R.A., 2004, Bankruptcy prediction with industry effects, Review of Finance 8, 537-569.

[11] Chava, S., Stefanescu, C., and Turnbull, S.M., 2006, Modeling Expected Loss, Working Paper.

[12] Claus, J. and Thomas, J., 2001, Equity Premia as Low as Three Percent? Evidence from Analysts ' Earnings Forecasts for Domestic and International Stock Markets, Journal of Finance 56(5), 1629-1666.

[13] Driessen, J., 2003, Is Default Event Risk Priced in Corporate Bonds?, Working Paper, University of Amsterdam.

[14] Duffie, D. and Lando, D., 2001, Term Structure of Credit Spreads with Incomplete Accounting Information, Econometrica 69(3), 633-664.

[15] Duffie, D./Saita, L./Wang, K., 2007, Multi-period corporate default prediction with stochastic covariates, Journal of Financial Economics 83, 635-665. 
[16] Duffie, D. and Singleton, K., 1999, Modeling Term Structures of Defaultable Bonds, Review of Financial Studies 12, 687-720.

[17] Duffie, D. and Singleton, K., 2003, Credit Risk - Pricing, Measurement, and Management, 1st ed., Princeton.

[18] Eom, Y.H., Helwege, J., and Huang, J.Z., 2000, Structural Models of Corporate Bond Pricing: An empirical analysis, Working Paper, Finance Department, Ohio State University, Columbus.

[19] Easton, P., Taylor, G., Shroff, P., and Sougiannis, T., 2002, Using Forecasts of Earnings to Simultaneously Estimate Growth and the Rate of Return on Equity Investments, Journal of Accounting Research 40, 657-676.

[20] Elton,E.J., Gruber, M.J., Agrwal,D., and Mann,C., 2001, Explaining the Rate Spread on Corporate Bonds, Journal of Finance 56, 247-277.

[21] Fama, E.F. and French, K.R., 1993, Common Risk Factors in the Returns of Stocks and Bonds, Journal of Financial Economics 33, 3-56.

[22] Fama, E.F. and French, K.R., 1996, Multifactor Explanations of Asset Pricing Anomalies, Journal of Finance 51, 55-84.

[23] Fama, E.F. and French, K.R., 2002, The Equity Premium, Journal of Finance 57(2), 636-659.

[24] Finger, C.C., Finkelstein, V., Pan, G., Lardy, J.-P., Ta, T., and Tierney, J., 2002, CreditGrades, Technical Document, RiskMetrics Group.

[25] Gebhardt, W., Lee, C., and Swaminathan, B., 2001, Toward an Implied Cost of Capital, Journal of Accounting Research 39(1), 135-176.

[26] Gordon, M., 1962, The Investment, Financing, and Valuation of the Corporation, Irwin Publishing.

[27] Huang, J. and Huang, M., 2005, How much of the Corporate-Treasury Yield Spread is Due to Credit Risk?: Results from a New Calibration Approach, Working Paper, Graduate School of Business, Standford University.

[28] Hull, J., 2005, Options, Futures and Other Derivatives, 6th rev. ed., New Jersey.

[29] Hull, J., Predescu, M., and White, A., 2004, The Relationship between Credit Default Swap Spreads, Bond Yields, And Credit Rating Announcements, Journal of Banking and Finance $28,2789-2811$.

[30] Hull, J., Predescu, M., White, A., 2005, : Bond Prices, Default Probabilities and Risk Premiums, Journal of Credit Risk 1(2), 53-60. 
[31] Ibbotson, 2006, International Equity Risk Premia Report 2006, Ibbotson Associates, Inc.

[32] Illmanen, A., 2003, Expected Returns on Stocks and Bonds, Journal of Portfolio Management $29(2), 7-28$.

[33] Leland, H.E. and Toft, K., 1996, Optimal Capital Structure, Endogenous Bankruptcy, and the Term Structure of Credit Spreads, The Journal of Finance 51, 987-1019.

[34] Liu, J., Longstaff, F., and Mandell, R., 2000, The market price of credit risk: An empirical analysis of interest rate swap spreads, Working Paper.

[35] Liu, J., Shi, J., Wang, J., and Wu, C., 2007, How much of the corporate bond spread is due to personal taxes?, Journal of Financial Economics 85(3).

[36] Löffler, G., 2004, Ratings versus market-based measures of default risk in portfolio governance, Journal of Banking and Finance 28, 2715-2746.

[37] Löffler, G. and Maurer, A., 2008, Incorporating the dynamics of leverage into default prediction, Working Paper.

[38] Mehra,R. and Prescott,E.C., 1985, The Equity Premium: A Puzzle, Journal of Monetary Economics 15(2), 145-161.

[39] Mehra, R., 2003, The Equity Premium: Why is it a Puzzle, Working Paper.

[40] Merton, R.C., 1974, On the pricing of corporate debt: The risk structure of interest rates, Journal of Finance 29, 449-470.

[41] Moody's Investors Service, 2007, Corporate Default and Recovery Rates, 1920-2006.

[42] Moody's KMV, 2007, EDF 8.0 Model Enhancements: Modeling Methodology.

[43] Musiela, M. and Rutkowski, M., 1997, Martingale Methods in Financial Modelling, Berlin u.a..

[44] Schönbucher, P.: Credit Derivatives Pricing Models, 1st ed., Chichester 2003.

[45] Shumway T., 2001, Forecasting bankruptcy more accurately: a simple hazard model, Journal of Business 74, 101-124.

[46] Zhou C., 1997, A jump-diffusion approach to modeling credit risk and valuing defaultable securities, Finance and Economics Discussion Paper. 